\title{
Nuclear lamina defects cause ATM-dependent NF-кB activation and link accelerated aging to a systemic inflammatory response
}

\author{
Fernando G. Osorio, ${ }^{1}$ Clea Bárcena, ${ }^{1}$ Clara Soria-Valles, ${ }^{1}$ Andrew J. Ramsay, ${ }^{1}$ Félix de Carlos, ${ }^{2}$ \\ Juan Cobo, ${ }^{2}$ Antonio Fueyo, ${ }^{3}$ José M.P. Freije, ${ }^{1,4}$ and Carlos López-Otín ${ }^{1,4}$ \\ ${ }^{1}$ Departamento de Bioquímica y Biología Molecular, Facultad de Medicina, Instituto Universitario de Oncología, Universidad de \\ Oviedo, 33006-Oviedo, Spain; ${ }^{2}$ Departamento de Cirugía y Especialidades Médico-Quirúrgicas, Instituto Asturiano de Odontología, \\ Universidad de Oviedo, 33006-Oviedo, Spain; ${ }^{3}$ Área de Fisiología, Departamento de Biología Funcional, Facultad de Medicina, \\ Instituto Universitario de Oncología, Universidad de Oviedo, 33006-Oviedo, Spain
}

\begin{abstract}
Alterations in the architecture and dynamics of the nuclear lamina have a causal role in normal and accelerated aging through both cell-autonomous and systemic mechanisms. However, the precise nature of the molecular cues involved in this process remains incompletely defined. Here we report that the accumulation of prelamin $\mathrm{A}$ isoforms at the nuclear lamina triggers an ATM- and NEMO-dependent signaling pathway that leads to NF-кB activation and secretion of high levels of proinflammatory cytokines in two different mouse models of accelerated aging (Zmpste24- ${ }^{--}$and Lmna ${ }^{G 609 G / G 609 G}$ mice). Causal involvement of NF-кB in accelerated aging was demonstrated by the fact that both genetic and pharmacological inhibition of NF-кB signaling prevents ageassociated features in these animal models, significantly extending their longevity. Our findings provide in vivo proof of principle for the feasibility of pharmacological modulation of the NF-kB pathway to slow down the progression of physiological and pathological aging.
\end{abstract}

[Keywords: nuclear envelope; longevity; progeroid laminopathies]

Supplemental material is available for this article.

Received June 5, 2012; revised version accepted September 4, 2012.

Aging is associated with the progressive and irreversible loss of tissue homeostasis. Several stressors have been related to this process, including DNA damage, telomere attrition, or accumulation of damaged macromolecules (Kirkwood 2005; Vijg and Campisi 2008). An exaggerated accumulation of cellular damage or the inefficient ability to respond to stress causes progeroid syndromes, characterized by a precocious manifestation of several features related to human aging (Burtner and Kennedy 2010). Most progeroid syndromes are caused by defective DNA repair mechanisms or by alterations in the nuclear lamina (Ramirez et al. 2007; Hoeijmakers 2009). The nuclear lamina is a complex structure that surrounds and protects the nuclear content, playing important roles in genome regulation, organization, and maintenance (Dechat et al. 2008). Covering the inner face of the nuclear membrane,

${ }^{4}$ Corresponding authors E-mail clo@uniovi.es

E-mail jmpf@uniovi.es

Article published online ahead of print. Article and publication date are online at http://www.genesdev.org/cgi/doi/10.1101/gad.197954.112. the nuclear lamina forms a protein network that provides a scaffold for nuclear envelope proteins and chromatin (Gruenbaum et al. 2005; Mekhail and Moazed 2010).

Alterations in the nuclear lamina affect nuclear structure and DNA integrity, leading to defects in DNA replication and repair processes and inducing the accumulation of different types of DNA damage (Worman and Foisner 2010). Thus, several mutations in lamins and lamin-binding proteins have been associated with a subgroup of progeroid syndromes known collectively as progeroid laminopathies (Worman et al. 2010). Among them, Hutchinson-Gilford progeria syndrome (HGPS) is one of the most comprehensively studied. HGPS patients show growth impairment, lipodystrophy, dermal and bone abnormalities, and cardiovascular alterations, leading to a dramatically shortened life span (Hennekam 2006; Merideth et al. 2008). HGPS is primarily caused by a de novo silent mutation within exon 11 of the LMNA gene encoding lamin A (c.1824C >T; p.Gly608Gly) (De Sandre-Giovannoli et al. 2003; Eriksson et al. 2003).

Lamin A, a core component of the nuclear lamina, undergoes a complex maturation process, including 
farnesylation, carboxyl methylation, and proteolytic processing by the metalloproteinase ZMPSTE24/FACE-1. The HGPS mutation c. $1824 \mathrm{C}>\mathrm{T}$ activates a cryptic splice donor site, leading to a truncated form of prelamin A, called LA $\Delta 50$ or progerin, which lacks a 50-residue-long fragment containing the cleavage site for ZMPSTE24. Accordingly, Zmpste24 $4^{-/-}$mice show a premature aging phenotype that phenocopies human HGPS (Bergo et al. 2002; Pendas et al. 2002; Osorio et al. 2011a). In all cases, the accumulation of farnesylated forms of prelamin A in the nuclear envelope leads to the nuclear abnormalities and functional defects characteristic of cells from HGPS patients and Zmpste24 ${ }^{-/-}$mice. Interestingly, progerin accumulation is also detected during normal aging, thereby adding a new level of interest to the study of the mechanisms that underlie progerin formation and accumulation (Scaffidi and Misteli 2006).

NF- $\mathrm{kB}$ transcription factors form a cytoplasmic sensor system responding to not only pathogen attack, but also a variety of external and internal danger signals, such as oxidative stress, hypoxia, and genotoxic stress (Perkins 2007; Hayden and Ghosh 2008). NF-кB active transcription factors are composed of dimeric combinations of members of the Rel family. In mammals, five different Rel family members have been identified: RelA (p65), RelB, c-Rel, NF-кB1 (p50 and its precursor, p105), and NF-кB2 (p52 and its precursor, p100), which can form heterodimers or homodimers (Hayden and Ghosh 2012). Many known stimuli that activate NF- $\mathrm{kB}$ require signaling through the conserved IKK complex, consisting of at least two catalytic subunits, IKK $\alpha$ and IKK $\beta$, and a regulatory subunit known as NEMO (also known as IKK $\gamma$ ). Activation of the NF- $\mathrm{kB}$ signaling pathway is one of the cellular responses evoked to maintain homeostasis after DNA damage (Janssens and Tschopp 2006). As part of the DNA damage response (DDR), activation of the kinase ataxia telangiectasia mutated (ATM) triggers a signaling pathway involving NEMO to directly link DNA damage events in the nucleus with the cytoplasmic activation of NF-кB (Miyamoto 2011). Thus, upon DNA damage, NEMO undergoes a sequence of post-translational modifications that includes sumoylation, ATM-mediated phosphorylation, and ubiquitylation (Huang et al. 2003; Wu et al. 2006). NEMO trafficking between the cytoplasm and nucleus is a consequence of these modifications and finally results in the activation of the IKK complex and the nuclear translocation of NF- $\mathrm{BB}$ active dimers (McCool and Miyamoto 2012).

NF-кB hyperactivation has been related to the aging process (Adler et al. 2007). In addition, aberrant NF-кB activation is well documented in numerous age-associated diseases, including neurodegeneration, osteoporosis, diabetes, sarcopenia, immunosenescence, or atherosclerosis (Tak and Firestein 2001; Le Saux et al. 2012). Given the links between accelerated aging, chronic DDRs, and NF-кB activation (Salminen et al. 2008; Ugalde et al. 2011a; Tilstra et al. 2012), we hypothesized that structural abnormalities in the nuclear envelope could activate the NF-кB pathway. Accordingly, we used two different progeroid mouse models to test this hypothesis and formulate potential therapeutic intervention strategies. Here we report that accumulation of prelamin A or progerin in the nuclear envelope of progeroid mice triggers a signaling pathway involving ATM and NEMO proteins to activate NF-кB. We also demonstrate that NF-кB-driven inflammation is responsible for the development of several important features of progeroid phenotypes. Notably, inhibition of the NF- $\mathrm{KB}$ pathway using genetic or pharmacological strategies was able to prevent these alterations, demonstrating the causal involvement of this inflammatory pathway in the pathogenesis of accelerated aging.

\section{Results}

\section{Zmpste24-deficient mice show NF-кB hyperactivation}

Zmpste24-deficient mice accumulate farnesylated prelamin $\mathrm{A}$ at the nuclear envelope and develop a progeroid syndrome that phenocopies most features of HGPS, including growth impairment, lipodystrophy, dermal and bone abnormalities, and shortened life span (Bergo et al. 2002; Pendas et al. 2002). Previous studies in Zmpste24 ${ }^{-/-}$ mice have revealed that prelamin A accumulation induces cellular senescence as well as important changes in nuclear dynamics (Varela et al. 2005; Osorio et al. 2010). On the other hand, NF- $\mathrm{kB}$ activation during aging has been reported in human and mouse tissues as well as in cells from HGPS patients (Adler et al. 2007; Kawahara et al. 2009; Tilstra et al. 2011).

To evaluate the activity of NF-кB in Zmpste24deficient mice, we first analyzed the transcriptional

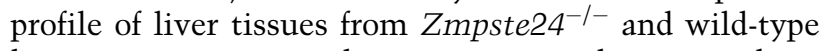
littermates. By using the gene set enrichment analysis (GSEA) algorithm, we identified a strong positive correlation between the transcriptional changes in tissues from mutant mice and a gene set composed of genes whose promoters contain the recognition sequence for NF- $\mathrm{kB}$ transcription factors (Fig. 1A; Supplemental Fig. 1). Next, we analyzed NF- $\mathrm{BB}$ activation in vivo in these progeroid mice using a gene reporter-based assay (Fig. 1B; Supplemental Fig. 2). To this end, we hydrodynamically delivered a plasmid vector encoding the firefly luciferase gene under the control of an NF- $\mathrm{kB}$ response element in Zmpste24 $4^{-/-}$and wild-type animals. This approach allowed us to quantify NF- $\mathrm{kB}$ activation in vivo by measuring the bioluminescence image obtained from these mice. Remarkably, the bioluminescence signal of Zmpste24-deficient mice was $>10$-fold higher as compared with age-matched control animals (Fig. 1B). NF-кB hyperactivation was further confirmed by NF-кB electrophoretic mobility shift assay (EMSA) using nuclear extracts from livers of Zmpste24 $4^{-1-}$ and control mice (Fig. 1C). Accordingly, reduced levels of the NF-кB inhibitor IкB $\alpha$ were also reproducibly observed in Zmpste24-deficient samples (Fig. 1C).

We next examined NF- $\mathrm{kB}$ activation in other tissues previously reported to be affected during the development

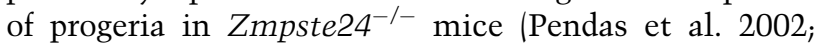
Varela et al. 2005). Thus, EMSA analysis of the thymus, spleen, kidney, and heart revealed an increase of $>2.5$-fold in NF-kB activity in Zmpste24 ${ }^{-/-}$tissues as compared 
A

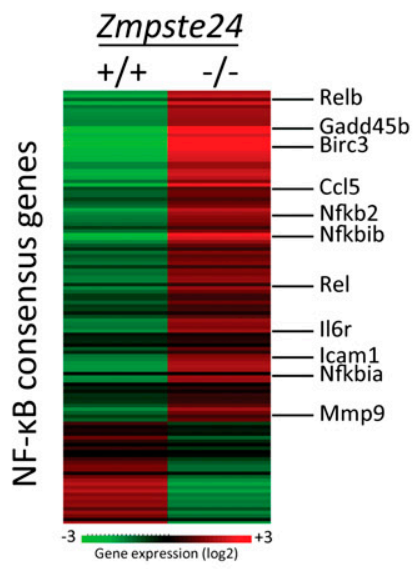

C

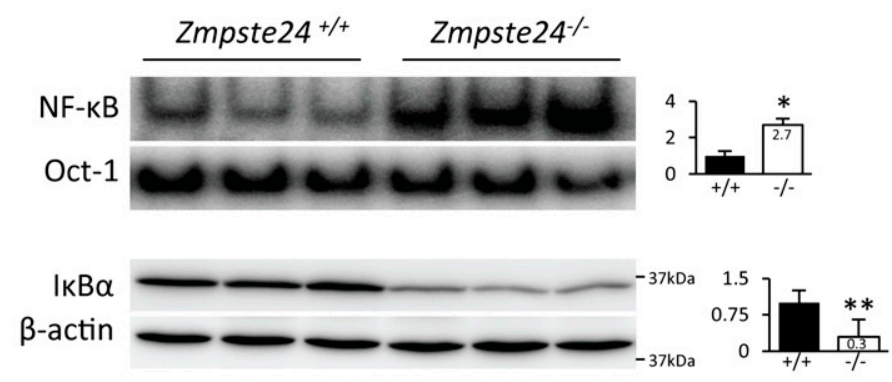

B

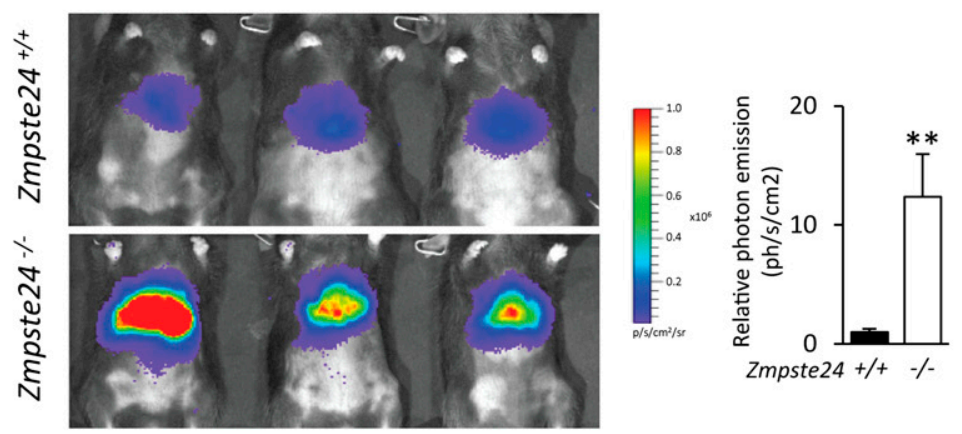

D

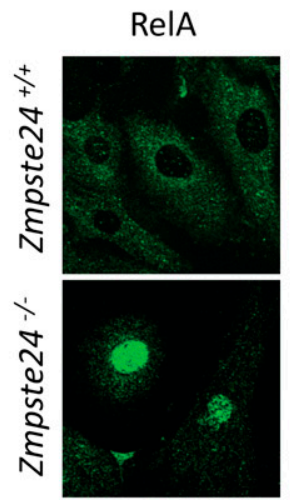

DAPI

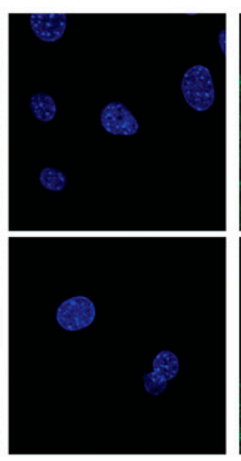

Merge

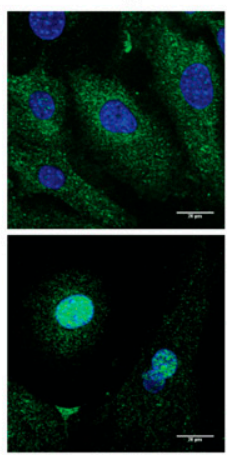

Figure 1. NF-кB hyperactivation in Zmpste24-deficient mice. (A) NF-кB target gene induction in Zmpste24-deficient mice. Heat map represents gene expression analysis (in Zmpste24-/- and wild-type livers) of genes that contain the consensus binding site for the NF$\kappa \mathrm{B}$ transcription factor, displayed as Log2 transformed expression signals. $(B)$ Hydrodynamic delivery of NF- $\mathrm{kB}-\mathrm{luciferase}$ gene reporter in the livers of 3-mo-old Zmpste24 ${ }^{-/-}$mice $(n=10)$ and age-matched control littermates $(n=10)$. The bioluminescence image was recorded as the photon flux per second and square centimeter, and three representative mice from each genotype are shown. Relative mean values are represented, and error bars indicate SEM. $P<0.01$, two-tailed Student's $t$-test. See also Supplemental Figure 2. $(C)$ NF$\kappa \mathrm{B}$ EMSA of livers from 3-mo-old Zmpste24 ${ }^{-/-}$mice $(n=3)$ and wild-type littermates $(n=3)$. Nuclear extracts were analyzed by using ${ }^{32} \mathrm{P}$-labeled NF-кB and Oct-1 probes. Western blot of $\mathrm{I} \kappa \mathrm{B} \alpha$ was performed using total liver extracts. $\beta$-Actin was used as loading control. Signals were quantified, and plots represent relative mean values \pm SEM. $\left({ }^{\star}\right) P<0.05 ;\left(^{\star \star}\right) P<0.01$, two-tailed Student's $t$-test. $(D)$ Representative image of immunofluorescence analysis using a RelA-specific antibody in fibroblasts from Zmpste24-deficient and wildtype mice. Bar, $20 \mu \mathrm{m}$.

with wild-type tissues (Supplemental Fig. 3). In agreement with this preferential nuclear localization of NF- $\kappa$ B in progeroid cells, immunofluorescence analysis revealed nuclear accumulation of RelA in $Z$ mpste $24^{-/-}$fibroblasts (Fig. 1D). Together, these data demonstrate that NF-кB is constitutively hyperactive in Zmpste24-deficient mouse tissues.

\section{ATM and NEMO cooperate to induce NF-кB activation upon prelamin $A$ accumulation}

Prelamin A accumulation at the nuclear envelope causes genomic instability and activates several DNA repair mechanisms that configure an integrated DDR (Liu et al. 2005; Ugalde et al. 2011b). ATM kinase has a central role in coordinating the cellular response to DNA damage (Lavin 2008; Bensimon et al. 2011) and is essential for nuclear activation of NF-кB (Wu et al. 2006). To gain insight into the putative relevance of this molecular pathway in the hyperactivation of NF-кB in tissues from Zmpste24-deficient mice, we first analyzed the status of ATM in these progeroid mice. As shown in Figure 2A, Western blot analysis of phospho-Ser1981-ATM revealed a 1.5-fold increase in the levels of active ATM in Zmpste24 $4^{-1-}$ mice as compared with wild-type animals.

As NEMO accumulation in the nucleus has been reported during DDR activation, we next prepared whole-cell and nuclear protein extracts from Zmpste24-deficient and control mice and analyzed NEMO levels by Western blot. This approach revealed that the nuclear levels of

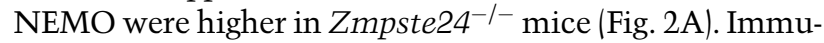
nofluorescence analysis of NEMO in mouse fibroblasts further confirmed this result (Fig. 2B). We next tested whether NF-кB activation was dependent on ATM activation. To this end, we chemically inhibited ATM and ablated ATM by using siRNAs (Supplemental Fig. 4) in fibroblasts derived from Zmpste24-deficient mice. Both ATM chemical inhibition and siRNA knockdown were 
A

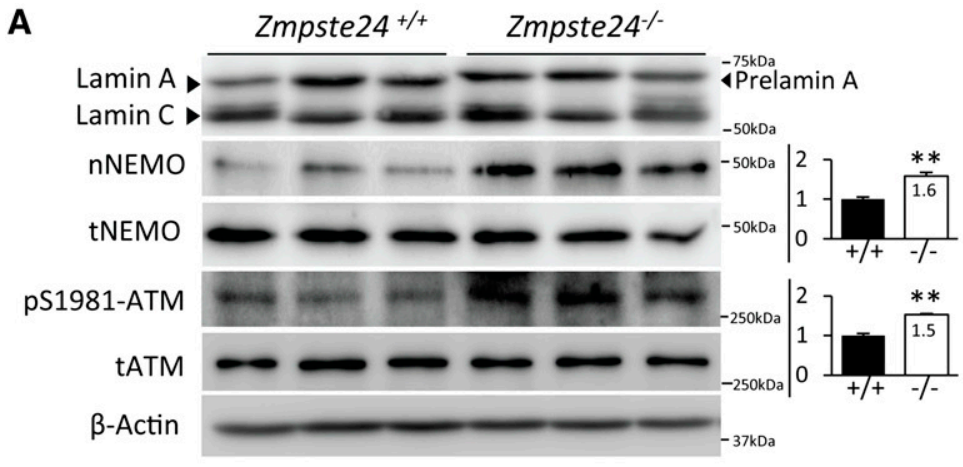

C

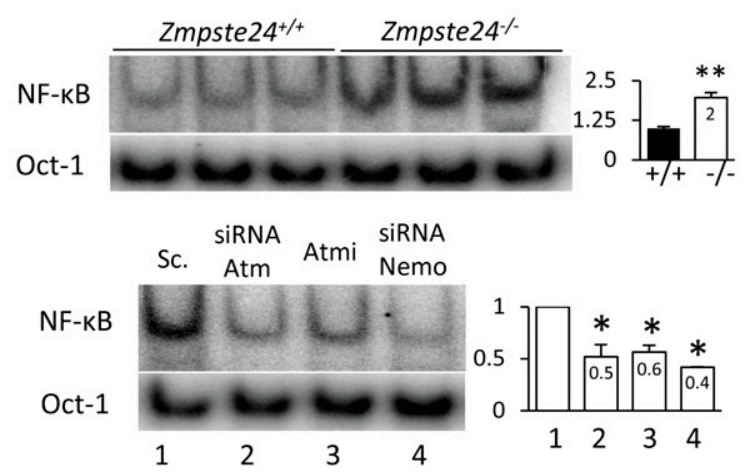

B
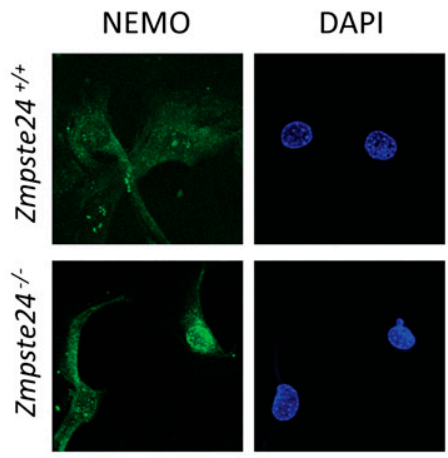

Merge

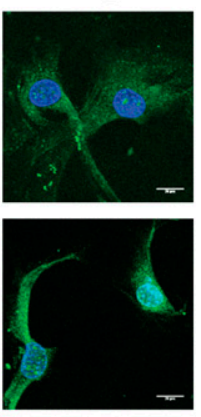

\section{D}
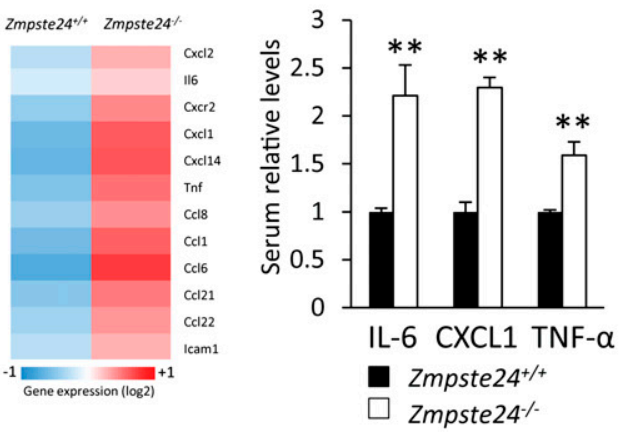

Figure 2. A signaling pathway involving ATM and NEMO activates NF-кB in Zmpste24-deficient mice. $(A)$ ATM activation and nuclear translocation of NEMO in Zmpste24 $4^{-1-}$ cells. Western blot of NEMO protein was performed in nuclear extracts from livers of 3-mo-old Zmpste24 ${ }^{-1-}$ mice $(n=3)$ and wild-type littermates $(n=3)$. Total NEMO, ATM, and pSer1981-ATM levels were analyzed in total extracts of the same animals. $\beta$-Actin was used as loading control. Signals were quantified and are represented as relative mean values \pm SEM. $\left(^{\star}\right) P<0.05 ;\left(^{\star \star}\right) P<0.01$, two-tailed Student's $t$-test. $(B)$ Nuclear staining of NEMO protein in fibroblasts from Zmpste24-deficient mice supports nuclear translocation upon prelamin A-induced nuclear stress. Representative images are shown. Bar, $10 \mu \mathrm{m} .(C)$ ATM and NEMO siRNA transfection experiments demonstrate causal involvement of these proteins in NF-кB activation. (Top panel) Nuclear extracts from $Z m p s t e 24^{-/-}$and $Z m p s t e 24^{+/+}$fibroblasts were analyzed by EMSA using ${ }^{32} \mathrm{P}-1 \mathrm{labeled} \mathrm{NF}-$ $\kappa \mathrm{B}$ and Oct-1 probes. (Bottom panel) siRNA transfection analysis by EMSA as well as ATM inhibitor KU55933 incubations were performed in three independent Zmpste24 ${ }^{-/-}$fibroblast cell lines, and the image shows a representative example. Signals were quantified and are represented as relative mean values \pm SEM. $\left.\left(^{\star}\right) P<0.05 ;{ }^{\star \star}\right) P<0.01$, two-tailed Student's $t$-test. See also Supplemental Figure 4. (D, left panel) Transcriptional analysis of SASP-related genes in Zmpste24-/- and wild-type livers. The right panel shows serum determinations of IL-6, CXCL1, and TNF- $\alpha$ in 3-mo-old Zmpste24 ${ }^{-/-}(n=5)$ and Zmpste24 $4^{+/+}$mice $(n=5)$. Plot represents relative mean values \pm SEM. $\left({ }^{\star}\right) P<0.05 ;\left(^{\star \star}\right) P<0.01$, two-tailed Student's $t$-test.

able to reduce the nuclear presence of NF-kB dimers to levels comparable with those of wild-type fibroblasts (Fig. $2 \mathrm{C}$. Moreover, and consistent with the proposed role of NEMO in nuclear NF- $\mathrm{kB}$ activation, NEMO siRNA also abrogated NF-kB activation (Fig. 2C).

The secretory phenotype of senescent cells contributes to the establishment of chronic inflammation in Zmpste24-deficient mice

Senescent cells secrete a plethora of interleukins, inflammatory cytokines, and growth factors that can affect surrounding cells, ultimately developing a secretory phenotype of senescent cells (SASP) (Kuilman and Peeper 2009; Coppe et al. 2010; Freund et al. 2010). Accordingly, we analyzed the transcriptional profile of SASP-associated genes in livers from Zmpste24-deficient mice and found a >1.5-fold up-regulation of several cytokine-encoding genes, such as I16, Cxc11, Cxcl2, Ccl8, and Tnf (Fig. 2D). Likewise, genes encoding different receptors and adhe- sion molecules, such as Cxcr2 or Icam1, were also found altered in these mutant animals. Moreover, serum levels of IL-6, CXCL1, and TNF- $\alpha$ were increased in Zmpste24deficient mice (Fig. 2D). These three cytokines are important mediators of inflammatory processes and have been related to aging and DDR (Kuilman and Peeper 2009; Biton and Ashkenazi 2011).

Together, these results provide experimental evidence that prelamin A accumulation induces NF- $\mathrm{KB}$ activation by an ATM- and NEMO-dependent pathway. Nuclear activation of NF- $\mathrm{\kappa B}$ contributes to the establishment of a secretory phenotype that could give rise to a systemic inflammatory situation.

RelA heterozygosity extends longevity and prevents the development of progeroid features in Zmpste24 ${ }^{-1-}$ mice

To test the specific contribution of NF- $\mathrm{kB}$ activation to the progeroid phenotype shown by Zmpste24-deficient 
mice, we used a previously described method of NF-кB genetic reduction (Kawahara et al. 2009; Tilstra et al. 2012) based on the use of RelA-haploinsufficient mice $\left(R e l A^{+/-}\right)$. RelA is a component of NF-кB pathway with essential developmental functions (Hayden and Ghosh 2004). Thus, RelA ${ }^{-/-}$mice present embryonic lethality, but $\mathrm{RelA}^{+/-}$mice are viable and apparently normal despite having reduced NF-кB activity (Beg et al. 1995). We crossed Zmpste24 ${ }^{+/-}$mice with RelA-haploinsufficient mice to create double-mutant $Z$ mpste24 ${ }^{+/-} \mathrm{RelA}^{+/-}$animals, which were then inbred to obtain Zmpste24 knockout mice with different dosages of RelA. As expected, we did not obtain any $R e l A^{-/-}$mice, as they were embryoniclethal, and $\mathrm{Zmpste} 24^{-/-} \mathrm{Re}^{+A^{+/}}$animals resulting from these crosses exhibited a phenotype identical to that of Zmpste24 $4^{-1-}$ mice (Pendas et al. 2002). However, Zmpste24 $4^{-/-} \mathrm{RelA}^{+/-}$showed improved body weights (Fig. 3A,B) and extended life spans as compared with Zmpste24 ${ }^{-/-}$RelA ${ }^{+/+}$animals (Fig. 3C). Significantly, the mean survival of $\mathrm{Zmpste} 24^{-/-} \mathrm{Re}^{+A^{+-}}$mice was extended from 118 to $146 \mathrm{~d}$, and the maximum survival was extended from 147 to $174 \mathrm{~d}(P<0.05)$ (Fig. 3C). Notably, increased life span in RelA-haploinsufficient mice corre- lated to a reduction in NF- $\mathrm{BB}$ activity in vivo, as assessed by hydrodynamic delivery of the NF- $\mathrm{B}$ luciferase reporter. Thus, Zmpste24 ${ }^{-/-}$RelA ${ }^{+-}$mice have lower bioluminescence signals as compared with $Z$ mpste24 ${ }^{-1-} \mathrm{RelA}^{+/}$ ${ }^{+}$, reaching levels similar to wild-type animals (Fig. 3D). Furthermore, NF-кB EMSA and Western blot experiments confirmed that RelA haploinsufficiency reduces the amount of nuclear RelA dimers (Fig. 3E; Supplemental Fig. 5) without affecting the levels of other NF-kB active members, such as p52 or RelB (Supplemental Fig. 5). Remarkably, no differences were found in nuclear levels

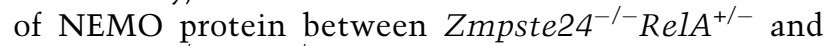
Zmpste24 ${ }^{-1-}$ RelA ${ }^{+/+}$animals, supporting the fact that NEMO translocation is an upstream event not affected by RelA haploinsufficiency.

The accumulation of farnesylated forms of prelamin A has been associated with profound dermal alterations, including loss of hypodermal adipocytes, decreased proliferation of keratinocytes, structural aberrations in hair follicles, and functional defects in stem cells present in this tissue (Espada et al. 2008; Sagelius et al. 2008; Wang

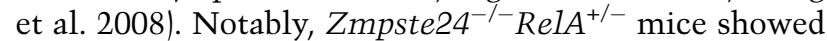
a complete recovery in most of the skin phenotypes
A

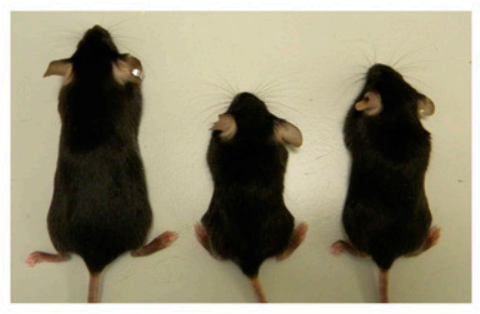

Zmpste24: + /+ RelA: $+/+$

D

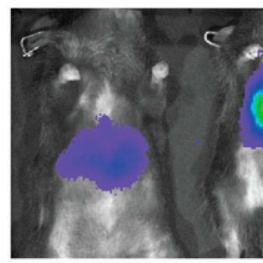

Zmpste24: +/+

RelA: $+/+$
B

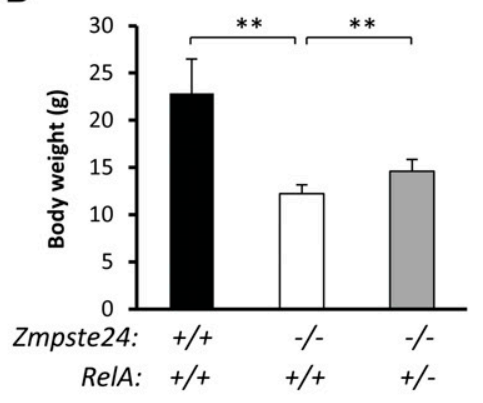

C

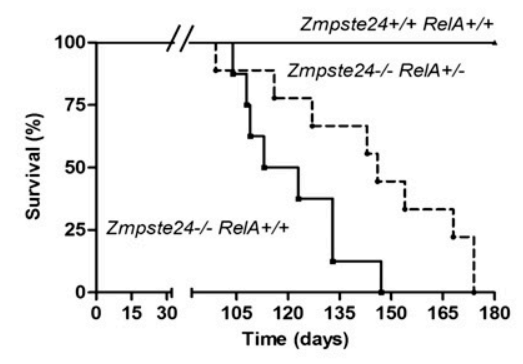

Figure 3. RelA haploinsufficiency extends longevity of Zmpste24-deficient mice by reducing NF- $\mathrm{B}$ activity. $(A)$ Representative

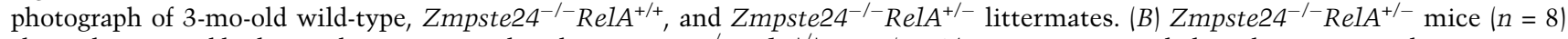
showed improved body weight as compared with $Z m p s t e 24^{-/}$RelA ${ }^{+/+}$mice $(n=7) . P<0.01$, two-tailed Student's $t$-test. Plot represents mean values \pm SEM. $(C)$ Kaplan-Meier survival plot showing the increase in life span of $Z m p s t e 24^{-/-}$RelA ${ }^{+/-}$mice $(n=8)$ as compared

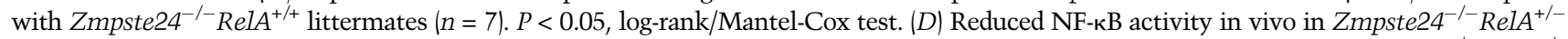

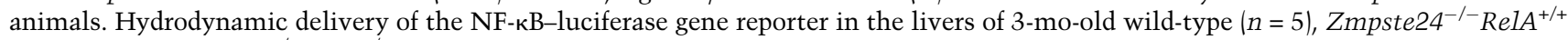
$(n=5)$ and Zmpste24 ${ }^{-/}$RelA ${ }^{+-}(n=5)$ mice. The bioluminescence image was recorded as the photon flux per second and square centimeter, and representative mice of each genotype are shown. Relative mean values are shown, and error bars indicate SEM. $P<0.01$

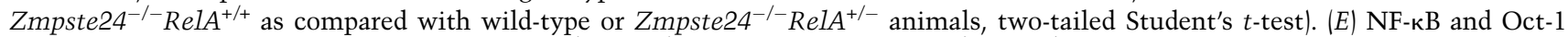
EMSA of 3-mo-old wild-type $(n=3), Z_{m p s t e 24^{-/}}$ReIA $^{+/+}(n=3)$, and Zmpste24 ${ }^{-1-}$ ReIA $^{+/-}(n=3)$ livers. Western blot shows reduced levels of RelA in haploinsufficient RelA ${ }^{+/-}$animals. $\beta$-Actin was used as loading control. Signals were quantified and are represented as relative mean values \pm SEM. $P<0.01$, two-tailed Student's $t$-test. 
studied, which are also present in normal aging. Thus, NF-кB blockade in the skin of Zmpste24-deficient mice increased cell proliferation, as indicated by increased expression of the proliferation marker Ki-67 (Fig. 4A).

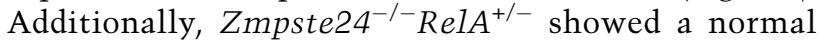
subcutaneous fat layer and well-structured hair follicles (Fig. 4A).

NF- $\kappa \mathrm{B}$ activity is also essential for a normal activity of the immune system, as demonstrated by the fact that mutations in several NF- $\mathrm{B}$ genes, including NEMO, cause immunodeficiency syndromes (Li and Verma 2002). In this regard, we observed that Zmpste24-deficient mice show marked histological alterations in the spleen and thymus, two of the most important lymphoid organs. Thus, Zmpste24-deficient mice exhibit reduced spleen size and cellularity as well as abnormal lymphoid follicles, which present an expansion of the mantle, disrupting the germinal centers (Fig. 4B). Notably, the thymus from $\mathrm{Zmpste} 24^{-1-}$ mice shows an involution process characterized by a reduction in tissue mass and thymic cellularity, loss of tissue structure, and abnormal architecture (Fig. 4B). Zmpste24 $4^{-/-}$RelA ${ }^{+/-}$mice display a notable improvement in both tissues. The spleen exhibits normal lymphoid follicles, whereas the thymus has recovered normal tissue mass, cellularity, and architecture, demonstrating the direct implication of NF- $\kappa$ B activation in the lymphoid alterations characteristic of Zmpste24-deficient mice.

We also studied bone architecture in order to explore the potential involvement of NF-кB activation in the bone abnormalities described in Zmpste24-deficient mice

A

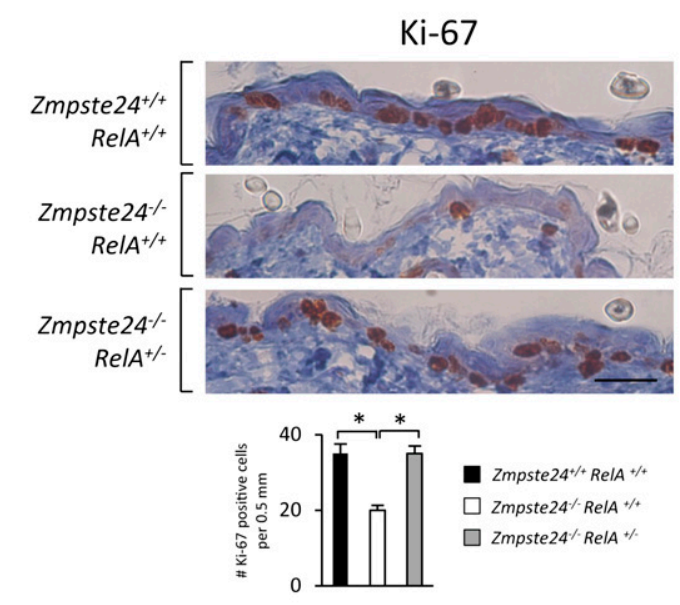

Skin

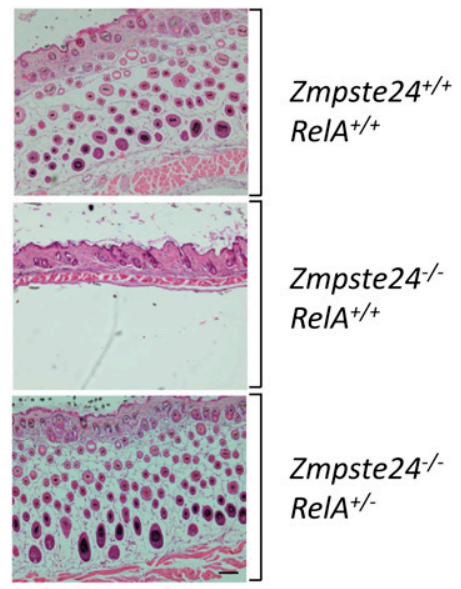

B
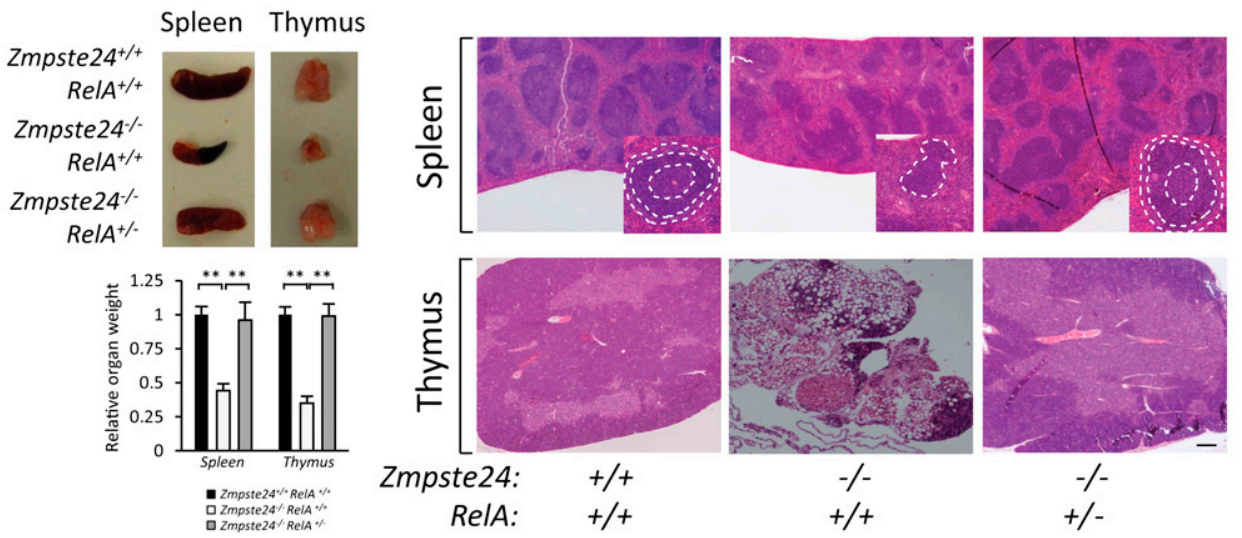

Figure 4. RelA heterozygosis prevents important progeroid features of $Z m p s t e 24^{-/-}$mice. $(A)$ Reversal of skin alterations by NF-кB

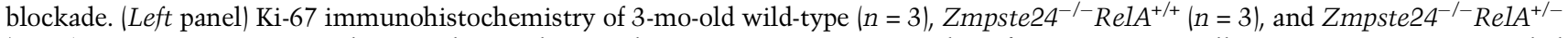
$(n=3)$ mice. Representative photographs are shown. Plot represents average number of Ki-67-positive cells \pm SEM. $P<0.01$, two-tailed Student's $t$-test. Bar, $30 \mu \mathrm{m}$. The right panel shows full recovery of the subcutaneous fat layer in 3-mo-old $\mathrm{Zmpste}^{-4^{-/}} \mathrm{RelA}^{+/-}$mice

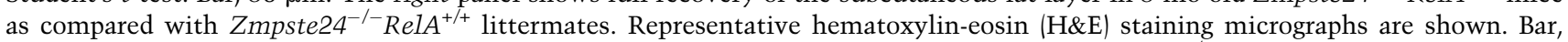
$100 \mu \mathrm{m}$. (B) Thymus and spleen involution in Zmpste24-deficient mice is prevented in the RelA ${ }^{+/-}$background. (Top left panel)

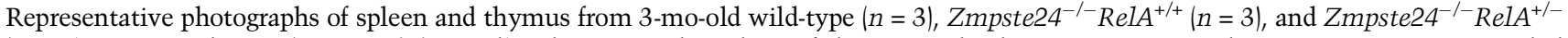
$(n=3)$ mice are shown. (Bottom left panel) Relative weight values of thymus and spleen are represented \pm SEM. $P<0.01$, two-tailed Student's $t$-test. The right panel shows representative micrographs from spleen and thymus tissues of wild-type, $\mathrm{Zmpste}^{-} 4^{-/-} \mathrm{RelA}^{+/+}$, and $Z$ mpste $24^{-/-}$RelA $^{+-}$animals. Spleen details show representative lymphoid follicles; different regions are circled by dotted white lines (germinal center and mantle and marginal zones). Note that the Zmpste $24^{-/-}$Rel $A^{+/+}$thymus shows a notable tissue involution where lymphoid tissue has been mostly replaced by adipose tissue. Bar, $100 \mu \mathrm{m}$. 
(de Carlos et al. 2008). To this end, microcomputed tomography $(\mu \mathrm{CT})$ analyses were performed on tibias

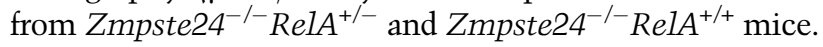
No differences were found between the two groups in the trabecular region, and only a slight improvement was found in the cortical region of bones from $\mathrm{Zmpste} 24^{-/-} \mathrm{ReIA}^{+-}$as compared with Zmpste24 ${ }^{-/-} \mathrm{RelA}^{+/+}$mice (Supplemental Fig. 6). These experiments demonstrate that NF-кB hyperactivation contributes to reducing the life span of progeroid mice and is responsible for some important features of the progeroid phenotype. Moreover, the phenotypic improvement of progeroid mice upon genetic reduction of NF-кB supports the feasibility of developing pharmacological strategies aimed at inhibiting this pathway to treat progeria.

\section{Sodium salicylate treatment efficiently prevents NF-кB activation and its associated alterations in Zmpste24-deficient mice}

Having shown that genetic inhibition of NF-кB extends longevity in Zmspte24-deficient mice, we asked whether the same biological effect could be achieved by using a pharmacological strategy. To this end, we chose sodium salicylate, a nonsteroidal anti-inflammatory drug that at high doses is able to efficiently inhibit the IKK complex and has been satisfactorily used to reduce NF-кB activation in animal models of muscular dystrophy (Cai et al. 2004). Thus, we treated Zmpste-24-deficient mice with sodium salicylate $(200 \mathrm{mg} / \mathrm{kg}$ per day), and both treated and control mice were weighted and observed during their lifetimes. Salicylate-treated Zmpste24 ${ }^{-/-}$mice showed improved body weights (Fig. 5A,B) and extended life spans as compared with nontreated Zmpste24deficient mice (Fig. 5C). Thus, the mean survival of salicylate-treated $\mathrm{Zmpste} 24^{-1-}$ mice was extended from 123 to $148 \mathrm{~d}$, and the maximum survival was extended from 151 to $243 \mathrm{~d}(P<0.01)$ (Fig. 5C).

NF-кB EMSA analysis of livers from treated and untreated mice demonstrated the targeted effect of salicylate on NF- $\mathrm{BB}$ activation (Fig. 5D), as treated mice showed decreased amounts of RelA dimers in the nucleus as well as reduced degradation of the NF- $\mathrm{B}$ inhibitor IкB $\alpha$ (Fig. 5D). Salicylate-treated Zmpste24 ${ }^{-/-}$mice showed
A

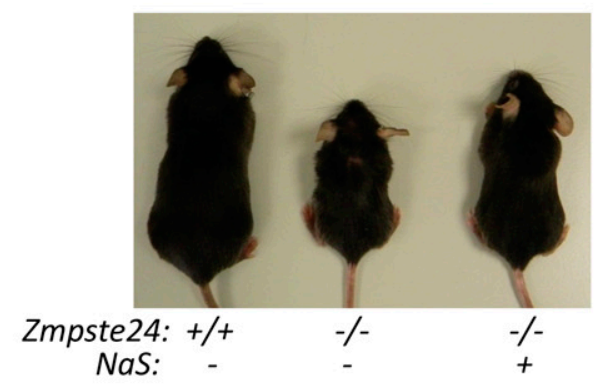

D
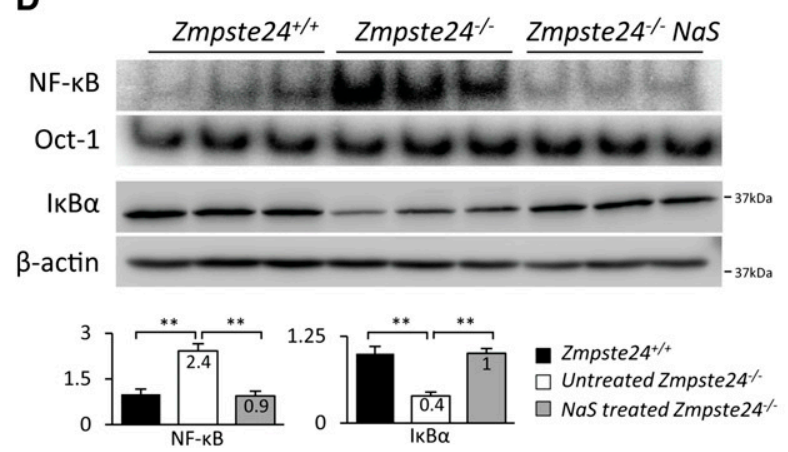

B

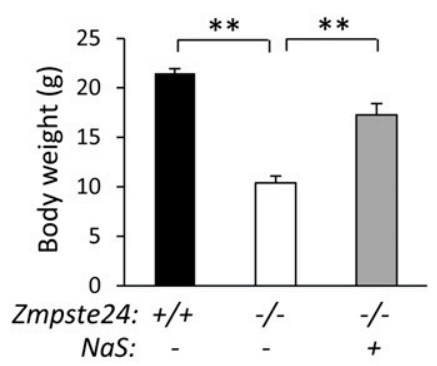

E

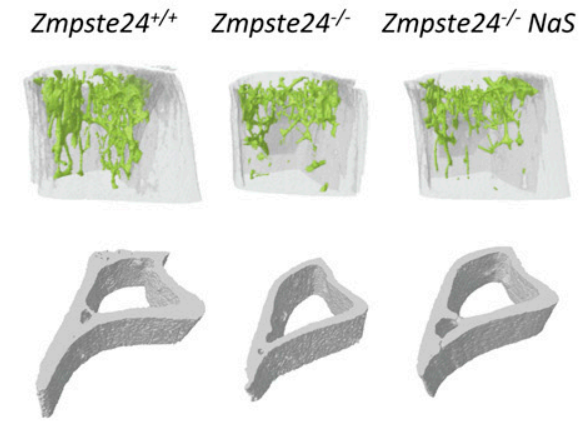

C

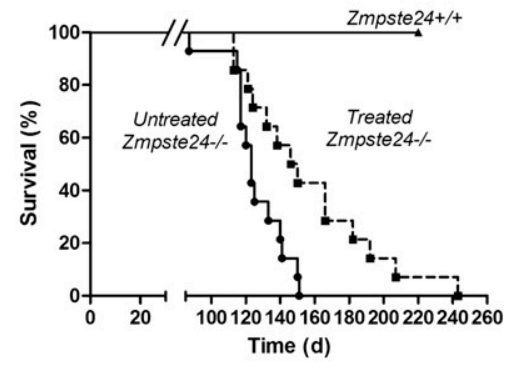

Figure 5. Sodium salicylate treatment extends longevity and prevents progeroid features of Zmpste24-deficient mice. (A) Representative photographs of 3-mo-old Zmpste24 ${ }^{+/+}$, untreated, and salicylate-treated Zmpste24-deficient mice. $(B)$ Sodium salicylate-treated Zmpste24 ${ }^{-/-}$mice $(n=12)$ showed improved body weight as compared with untreated $Z$ mpste24 ${ }^{-1-}$ mice $(n=12)$. Plot represents weight mean values \pm SEM. $P<0.01$, two-tailed Student's $t$-test. $(C)$ Kaplan-Meier survival plot showing the increase in life span of salicylate-treated Zmpste24 ${ }^{-1-}$ mice $(n=12)$ as compared with untreated Zmpste24 ${ }^{-1-}$ littermates $(n=12) . P<0.01$, log-rank/MantelCox test. $(D)$ Liver NF-кB and Oct-1 EMSA analysis demonstrates effective NF-кB inhibition in salicylate-treated Zmpste24-deficient mice. Western blot of IкB $\alpha$ was performed in total liver extracts. $\beta$-Actin was used as loading control. Signals were quantified and are represented as relative mean values \pm SEM. $P<0.01$, two-tailed Student's $t$-test. (E, left panel) Representative three-dimensional image generated from $\mu \mathrm{CT}$ analysis of tibias from 3-mo-old Zmpste24 ${ }^{+/+}(n=3)$, untreated $(n=3)$, and treated $Z \mathrm{mpste} 24^{-/-}(n=3)$ littermates. The right panel contains a quantitative analysis of relative bone volumes (bone volume/tissue volume [BV/TV]) and cortical thickness. Mean values are represented, and error bars indicate SEM. $P<0.05$ as compared treated and untreated Zmpste24-deficient mice, twotailed Student's $t$-test. 
an increase in cell proliferation, subcutaneous fat layer thickness, and normal hair follicles in the skin (Supplemental Fig. 7). Moreover, this treatment also prevented thymic and spleen involution, with these organs having a size similar to wild-type organs (Supplemental Fig. 8). Notably, bone architecture analysis revealed no significant changes in the trabecular region upon salicylate treatment. However, treated Zmpste24-deficient mice showed significantly improved cortical regions (Fig. 5E). This effect of salicylate treatment may derive from the known inhibitory effect of this compound on the synthesis of prostaglandins involved in bone homeostasis (Ricciotti and FitzGerald 2011). In summary, these data demonstrate that salicylate treatment is effective at inhibiting NF- $\kappa$ B activation in vivo and at significantly extending the longevity of progeroid Zmpste24-deficient mice.

\section{NF- $\kappa$ B is hyperactivated in Lmna $6609 G / G 609 G$ mice}

We recently generated a knock-in mouse strain carrying the most frequent HGPS mutation (Lmna c.1827C>T; p.Gly609Gly) (Osorio et al. 2011a). Lmna $a^{G 609 G / G 609 G}$ mice accumulate progerin and phenocopy the main clinical manifestations of HGPS, being a valuable model for the study of progeroid syndromes as well as for the preclinical evaluation of approaches aimed at preventing the pathological features of this condition. Comparison of transcriptional profiles from $L m n a^{G 609 G / G 609 G}$ and $\mathrm{Lmna}^{+/+}$mouse livers using GSEA showed a significant correlation between transcriptional alterations detected and the gene set that contains NF-кB-regulated genes (Supplemental Fig. 9). Next, we analyzed the NF-кB activation status in Lmna ${ }^{G 609 G / G 609 G}$ mice. Hydrodynamic delivery of the NF-кB luciferase reporter showed that mutant mice have an eightfold increase in bioluminescent signal (Fig. 6A) as compared with control littermates, indicating that these mutant mice present an activation of the NF- $\kappa$ B pathway similar to that observed in Zmpste24-deficient animals. These results were also confirmed by NF-кB EMSA experiments and $\mathrm{I} \kappa \mathrm{B} \alpha$ Western blot analysis using nuclear extracts from control and mutant liver samples (Fig. 6B).

The nuclear accumulation of progerin activates ATM kinase, as revealed by the increased amounts of phosphoSer1981-ATM present in Lmna ${ }^{G 609 G / G 609 G}$ samples (Fig. 6B). Consequently, NEMO accumulation in the nucleus supports the view that both prelamin A and progerin activate NF-кB through the same molecular mechanism. Serum levels of IL-6, CXCL1, and TNF- $\alpha$ were also increased in Lmna ${ }^{G 609 G / G 609 G}$ mice (Fig. 6C), which is in agreement with the systemic inflammation condition described above for Zmpste24-deficient mice and could be responsible for the similar immunological alterations found in Lmna ${ }^{G 609 G / G 609 G}$ mice (Supplemental Fig. 10).

To explore the possible occurrence of these alterations in human progeria, we first performed an EMSA analysis on HGPS fibroblasts. This study revealed a twofold increase in NF- $\mathrm{B}$ activity in progeria cells (Supplemental Fig. 11A). HGPS cells also showed increased levels of phospho-Ser1981-ATM and nuclear NEMO, suggesting that NF- $\kappa$ B activation in these human progeria cells results from the same mechanism as in the animal models described above. To gain insight into the potential relevance of this phenomenon during normal human aging, we analyzed NF- $\mathrm{KB}$ activation in fibroblasts from aged healthy donors. As shown in Supplemental Figure 11B, cells from advanced age donors showed a fivefold increase in NF- $\mathrm{B}$ activity as compared with fibroblasts obtained from young donors. In addition, aged fibroblasts showed increased ATM activation and nuclear NEMO translocation (Supplemental Fig. 11B), supporting that ATM- and NEMO-dependent NF- $\kappa \mathrm{B}$ activation could be at least in part responsible for the increased inflammation observed during normal aging (Adler et al. 2007).

\section{Pharmacological inhibition of NF- $\mathrm{B}$ extends longevity in the Lmna ${ }^{G 09 G / G 609 G}$ model of HGPS}

Currently, Lmna ${ }^{G 609 G / G 609 G}$ mice represent the best animal model available for the preclinical testing of therapeutic approaches for both HGPS and the age-associated pathologies derived from progerin accumulation in normal aging. Thus, aiming to provide preclinical proof of concept of the feasibility of using nonsteroidal antiinflammatory drugs to prevent the pathological consequences of progerin accumulation, we decided to extend the salicylate treatment results to the $L m n a^{G 609 G / G 609 G}$ mouse strain. To this end, we treated Lmna $6609 \mathrm{G} / \mathrm{G} 609 \mathrm{G}$ mice with sodium salicylate $(200 \mathrm{mg} / \mathrm{kg}$ per day) and found that salicylate-treated animals showed improved body weight as well an extended life span as compared with untreated mice (Fig. 6D-F). Moreover, the mean survival of salicylate-treated mice was extended from 107 to $152 \mathrm{~d}$, and the maximum survival was extended from 114 to $180 \mathrm{~d}(P<0.01)$.

Together, these results demonstrate that hyperactivation of the NF-кB pathway plays an important role in the development of aging-associated pathologies derived from the accumulation of abnormal lamin A precursors at the nuclear lamina. Moreover, these data provide evidence of the feasibility of developing anti-aging strategies based on the use of anti-inflammatory compounds.

\section{Discussion}

Over recent years, mechanistic studies on human aging have gained new insights from the elucidation of the molecular defects underlying the development of accelerated aging syndromes. These complex and dramatic diseases result from the combined action of both cellautonomous and systemic alterations (Marino et al. 2008; Osorio et al. 2011b). Thus, nuclear envelope defects causative of progeroid laminopathies lead to perturbations in cellular pathways, including p53-dependent cell senescence, deregulation of the somatotroph axis, and changes in metabolic master regulators (Lammerding et al. 2004; Varela et al. 2005; Scaffidi and Misteli 2008; Marino et al. 2010). Moreover, secretion of signaling molecules by affected cells could be a major contributor to progeria development, as secreted molecules can act on distant organs, leading to an amplifying cascade of aged signals. 
A

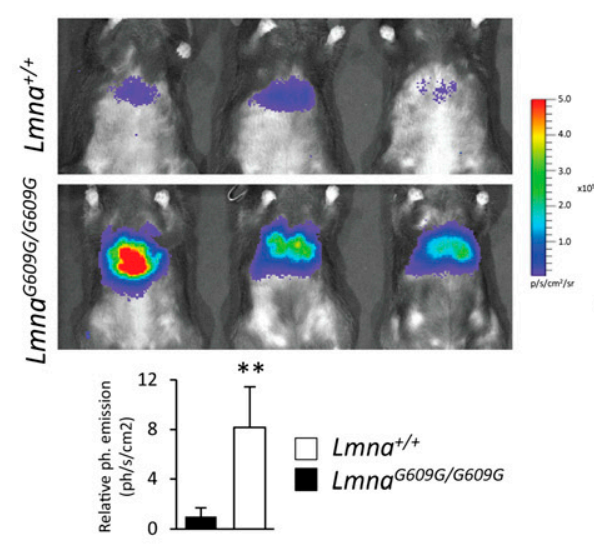

D

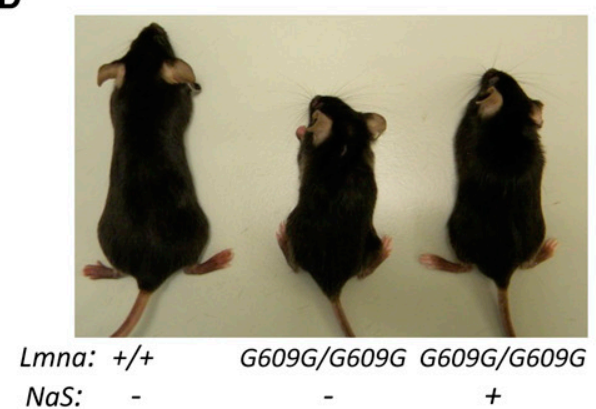

B

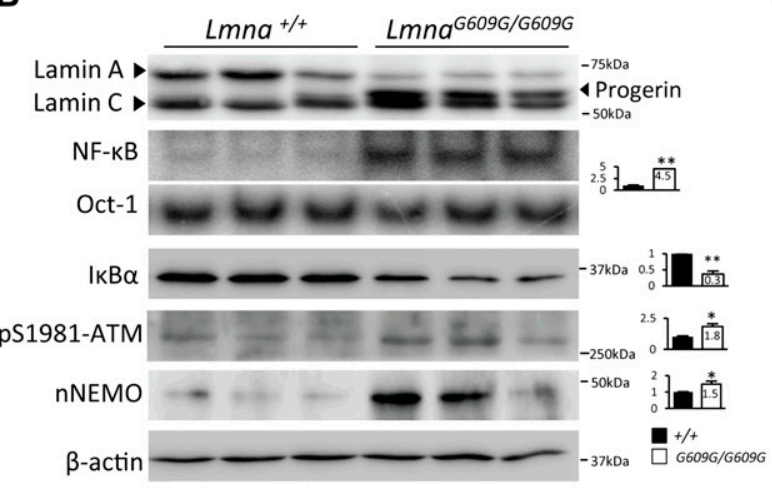

C

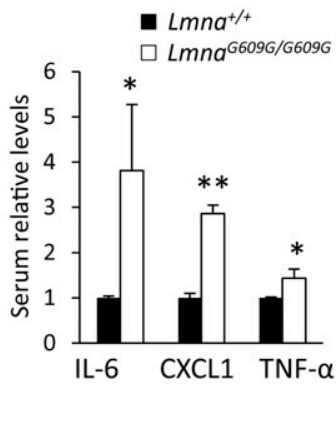

E

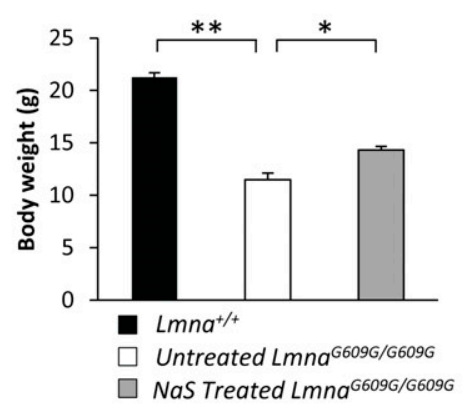

$\mathbf{F}$

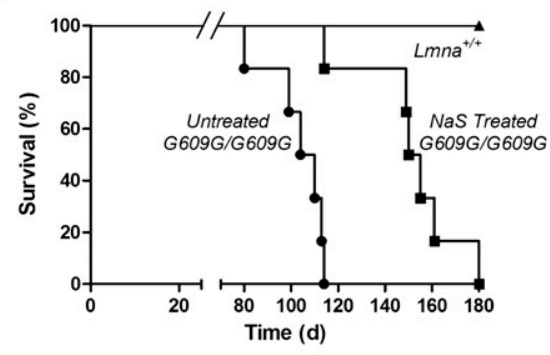

Figure 6. Salicylate treatment reduces NF-кB hyperactivation and extends longevity in $L m n a^{G 609 G / G 609 G}$ mice. (A) Lmna ${ }^{G 609 G / G 609 G}$

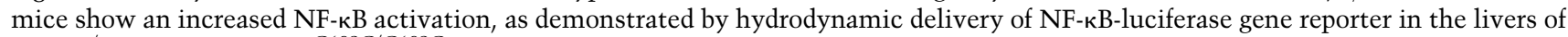
$\mathrm{Lmna}^{+/+}(n=5)$ and Lmna ${ }^{G 609 G / G 609 G}(n=5)$ mice. The bioluminescence image was recorded as the photon flux per second and square centimeter, and three representative mice from each genotype are shown. Plot represents relative mean values, and error bars indicate SEM. $P<0.01$, two-tailed Student's $t$-test. $(B)$ NF-кB activation in Lmna ${ }^{G 609 G / G 609 G}$ mouse livers. Western blot of lamin A/C isoforms

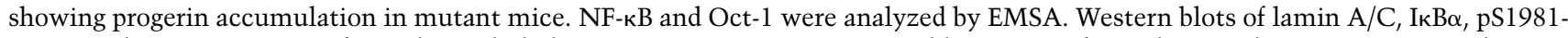
ATM, and $\beta$-actin were performed in whole-liver extracts. NEMO Western blot was performed in nuclear extracts. Signals were quantified and are represented as relative mean values \pm SEM. $\left(^{\star}\right) P<0.05 ;\left(^{\star \star}\right) P<0.01$, two-tailed Student's $t$-test. (C) Serum determinations of IL-6, CXCL1, and TNF- $\alpha$ in 3-mo-old $L m n a^{+/+}(n=5)$ and $L m n a^{G 609 G / G 609 G}(n=5)$ mice. Plot represents relative mean

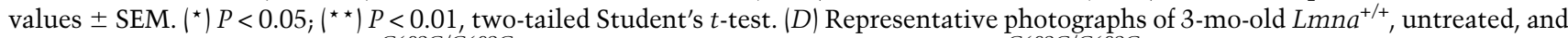
sodium salicylate-treated $L m n a^{G 609 G / G 609 G}$ mice. $(E)$ Sodium salicylate-treated Lmna ${ }^{G 609 G / G 609 G}$ mice $(n=6)$ showed improved body weight as compared with untreated $L m n a^{G 609 G / G 609 G}$ mice $(n=6)$. Plot represents weight mean values \pm SEM. $P<0.01$, two-tailed Student's $t$-test. $(F)$ Kaplan-Meier survival plot showing a significant increase in the life span of salicylate-treated $L m n a^{G 609 G / G 609 G}$ mice $(n=6)$ as compared with $L m n a^{G 609 G / G 609 G}$ littermates $(n=6) . P<0.01$, log-rank/Mantel-Cox test.

However, little is known about the nature of systemic factors involved in aging or aging-like processes as well as the mechanisms connecting nuclear defects to perturbations in such systemic factors. Here, we present an ATMdependent NF-kB activation pathway that links nuclear lamina defects to systemic inflammation. We also demonstrate in vivo the causal role for this pathway in the emergence of age-associated pathologies and illustrate the feasibility of targeting this signaling cascade for the treatment of premature aging symptoms.

By using two different mouse models of progeroid laminopathy (Zmpste24-deficient and Lmna ${ }^{G 609 G}$ mice), we showed that accumulation of prelamin $\mathrm{A} /$ progerin at the nuclear lamina activates the NF-кB pathway in an ATM- and NEMO-dependent manner, illustrating that alterations in the nuclear architecture generate stress signals that activate important DNA damage sensors. In this context, ATM and NEMO act coordinately to activate NF- $\mathrm{kB}$, as demonstrated by the finding that their respective inhibition prevents prelamin A-induced NF- $\mathrm{BB}$ activation. Consistent with the observed activation of NF- $\mathrm{KB}$ signaling in Zmpste24-/- and LmnaG609G/G609G progeroid mice, several cytokines and adhesion molecules are strongly up-regulated in cells and tissues from these mice, likely contributing to the initiation and maintenance of an inflammatory response. Among the plethora of proinflammatory cytokines secreted by senescent cells, we propose that IL-6, CXCL1, and TNF- $\alpha$ may have essential roles in progeria development by nonautonomous stimulation of surrounding cells through the activation of their cognate cell surface receptors and signal transduction pathways (Coppe et al. 2010; Freund et al. 2010). Thus, systemically increased levels of cytokines amplify the inflammatory stimuli and are implicated 
in the establishment of a feed-forward signaling process (Biton and Ashkenazi 2011). Since senescent cells are potentially time-persisting, the continued production of cytokines and the subsequent NF- $\mathrm{kB}$ activation lead to an increased inflammation in progeroid mice that contributes to age-related wasting and dramatically shortens organismal life span (Fig. 7).

According to our results, NF-кB could be regarded as a major regulator of accelerated aging, as demonstrated by the fact that NF-кB blockade significantly increases life span in both Zmpste24 ${ }^{-1-}$ and Lmna ${ }^{G 609 G / G 609 G}$ progeroid mice. Furthermore, the NF-кB blockade strategies used in this study have allowed us to provide new molecular insights into the involvement of NF-кB in dermal and immunological homeostasis. The primary manifestations of accelerated aging in skin affect cell proliferation, hair follicles, and the subcutaneous fat layer (Sur et al. 2008). NF-кB blockade was able to prevent these alterations, demonstrating a causal role of NF- $\mathrm{KB}$ deregulation in ageassociated defects in skin homeostasis. A similar situation has been shown in lymphoid organs, which is of special interest, as thymic involution is considered one of

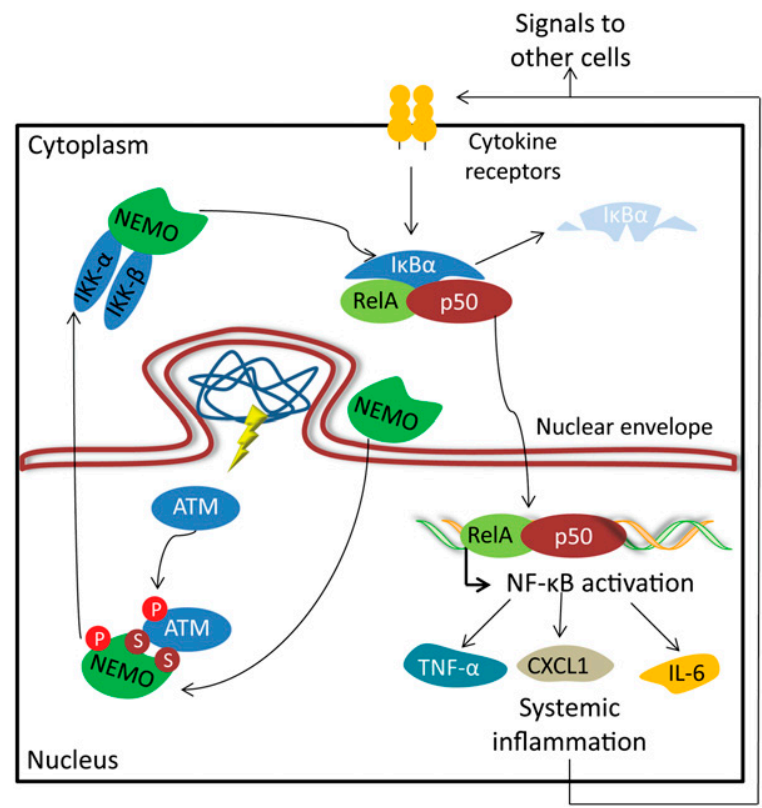

Figure 7. A model depicting ATM- and NEMO-mediated NF$\kappa \mathrm{B}$ activation upon accumulation of prelamin A isoforms. Nuclear envelope alterations caused by the accumulation of prelamin A isoforms trigger a nuclear stress pathway involving ATM and NEMO proteins. As a consequence of prelamin A/progerin accumulation, ATM is activated, and NEMO is translocated into the nucleus. NEMO phosphorylation by ATM induces their translocation out of the nucleus to activate the cytoplasmic IKK complex. Subsequent NF- $\mathrm{KB}$ activation triggers an inflammatory-associated transcriptional program that leads to the secretion of IL-6, CXCL1, and TNF- $\alpha$. Increased levels of senescence-associated cytokines cause systemic inflammation by acting over distant cells and tissues. Systemic inflammation amplifies a cascade of aged signals, critically affecting tissue homeostasis and finally reducing the life span of progeroid mice. the leading regulators of aging (Aw and Palmer 2011). The reduction in tissue mass and cellularity and the loss of tissue structure leads to a decline in naive T-cell output as well as to the occurrence of changes in the peripheral T-cell compartment that contribute to the clinical signs of immunosenescence (Hale et al. 2010). Consistent with these observations, we demonstrated in this study that NF-кB hyperactivation and the systemic inflammation derived therefrom drive thymus and spleen involution and that NF- $\mathrm{kB}$ inhibition is able to prevent these agerelated alterations.

Although the biological significance of NF- $\mathrm{KB}$ activation during aging is not completely clear, the findings reported herein, together with the fact that other models of normal and accelerated aging show increased levels of NF-кB activity (Kawahara et al. 2009; Rodier et al. 2009), support the idea that inflammation is a major regulator of the aging process. The mechanism by which NF-кB signaling is activated with age also remains largely unexplored, but our data indicate that the nuclear envelope abnormalities occurring in both normal and premature aging (Scaffidi and Misteli 2006) may contribute, at least in part, to the activation of this inflammatory pathway. The primary function of NF- $\mathrm{kB}$ activation in response to nuclear envelope defects could be to protect damaged cells against apoptosis (Wang et al. 1999; Salminen et al. 2011). Since a proper clearance of senescent cells by the immune system seems to be crucial for homeostasis maintenance in aging and cancer (Baker et al. 2011; Kang et al. 2011), both NF-kB hyperactivation and the subsequent age-related immunological decline could be compromising an appropriate response against age-accumulated senescent cells.

The results of the present work also suggest that the use of nonsteroidal anti-inflammatory drugs, alone or in combination with statins and aminobisphophonates (Varela et al. 2008), could be useful for the treatment of accelerated aging-associated alterations occurring during the course of progeroid laminopathies (Hennekam 2006; Merideth et al. 2008; Puente et al. 2011). Moreover, pharmacological modulation of the NF-кB pathway also could be of interest for slowing down the progression of physiological aging (Rando and Chang 2012). The identification of NF- $\kappa B$ signaling activation in mouse models with accelerated aging also provides further in vivo support for the provocative proposal that the maintenance of the aged state requires an active signaling program and that age-linked phenotypes can be substantially reversed by intervention on the activity of individual genes (Adler et al. 2007; Freije and Lopez-Otin 2012; Rando and Chang 2012). Accordingly, we suggest that the progeroid mice used in this study may represent a valuable tool for further exploration of this proposal due to their faithful recapitulation of the biological dysfunctions normally associated with advanced age. Likewise, we propose that these progeroid mice are an essential tool for the development of putative rejuvenation strategies aimed at controlling the inflammatory responses driven by NF- $\mathrm{kB}$ signaling that occur during both normal and pathological aging. 


\section{Materials and methods}

\section{Antibodies and reagents}

Antibodies specific for lamin A/C (sc-6215, Santa Cruz Biotechnology), IкB $\alpha$ (4812, Cell Signaling), RelA (8242, Cell Signaling), NEMO (2685, Cell Signaling), ATM (2873, Cell Signaling), phospho-Ser1981-ATM (mouse: 200-301-400, Rockland Laboratories; human: 5883S, Cell Signaling), p52 (sc-7386, Santa Cruz Biotechnology), RelB (sc-48366, Santa Cruz Biotechnology), Ki67 (KI681C01, DCS-Innovative Diagnostik-Systeme), $\alpha$-tubulin (T6074, Sigma), and $\beta$-actin (AC-40, Sigma) were used in this study for Western blot, immunofluorescence, and immunohistochemistry experiments. The ATM inhibitor KU55933 was obtained from Calbiochem.

\section{Mice}

We generated and genotyped Zmpste24-/- and Lmna ${ }^{G 609 G}$ mice as previously described (Pendas et al. 2002; Osorio et al. 2011a). RelA ${ }^{+/-}$mice were obtained from Jackson Laboratories. Zmpste $24^{+/-}$and RelA ${ }^{+/-}$were crossed, and $\mathrm{Zmpste} 24^{+/-} \mathrm{ReIA}^{+/-}$ progeny were interbred to obtain $Z m s p t e 24^{-/-} \mathrm{RelA}^{+/-}$mice. We administrated sodium salicylate $(200 \mathrm{mg} / \mathrm{kg}$ per day; SigmaAldrich) in PBS intraperitoneally to mice every day. Neither vehicle alone nor sodium salicylate treatment produced any apparent damage or stress responses in mice. We performed $\mu \mathrm{CT}$ analysis of tibias with a $\mu \mathrm{CT}$ SkyScan 1172 system (SkyScan). For histology analysis, we fixed samples with $4 \%$ paraformaldehyde in PBS, processed the resulting preparations into serial paraffin sections, and stained each with hematoxylin and eosin (H\&E). All of the animal experiments were performed in accordance with the guidelines of the Committee for Animal Experimentation of the Universidad de Oviedo.

\section{Hydrodynamic delivery of an NF-кB-luciferase gene reporter}

A plasmid containing a firefly luciferase gene under the control of a minimal CMV promoter and tandem repeats of the NFKB transcriptional response element was injected by using the hydrodynamic technique previously described (Herweijer and Wolff 2007). In brief, $10 \mu \mathrm{g} / \mathrm{mL}$ solution of the plasmid was prepared in sterile Ringer's buffer at room temperature. Mice were anaesthetized, and the lateral tail vein was accessed with a 21-gauge needle. Administration of the solution $(1 \mathrm{~mL} / 10 \mathrm{~g})$ was performed without extravasation.

\section{Bioluminescent imaging and analysis}

Mice were anaesthetized and injected intraperitoneally with $200 \mu \mathrm{L}$ of D-luciferin solution (15 g/L in PBS; Melford Laboratories). Imaging was completed between 2 and $5 \mathrm{~min}$ after injection with a Xenogen IVIS system coupled to Living Image acquisition and analysis software (Xenogen). Photon flux was calculated for each mouse by using a rectangular region of interest. This value was scaled for each mouse to a comparable background value. Represented values were recorded $7 \mathrm{~d}$ after injection to avoid any potential interference caused by experimental procedure-induced liver inflammation.

\section{Cell culture and siRNA delivery}

We extracted mouse fibroblasts from 15-wk-old ears as previously described (Varela et al. 2005). We maintained cultures in Dulbecco's modified Eagle's medium (Gibco) supplemented with $10 \%$ fetal bovine serum (Gibco) and $1 \%$ antibiotic anti- mycotic (Gibco). Studies with primary mouse fibroblasts were performed at postnatal day 3 (P3). HGPS (AG01972) and control fibroblasts (AG10803) were obtained from Coriell Cell repository. Dermal fibroblasts derived from young (GM05565, 3-yr-old; and GM00038, 9-yr-old) and advanced age donors (AG04059, 96yr-old) were obtained from Coriell Cell repository, except the JM0097Y cell line that was obtained directly from a 97-yr-old donor. For transfection of siRNAs, we followed the manufacturer's instructions (Stealth siRNAs, Life Technologies). Briefly, cells were plated at low density $(30 \%-50 \%)$, and up to $150 \mathrm{pg}$ of siRNA was added with $7.5 \mu \mathrm{L}$ of Lipofectamine RNAiMAX (Life Technologies). The same procedure was repeated after $4 \mathrm{~h}$, and analyses were performed $48 \mathrm{~h}$ after the first transfection. For pharmacological inhibition of ATM kinase activity, cells were incubated for $12 \mathrm{~h}$ in the presence of $10 \mu \mathrm{M}$ KU55933 ATM inhibitor.

\section{EMSA}

Nuclear extracts from cells were prepared as described previously (Schreiber et al. 1989). For the preparation of nuclear extracts from tissues, a slightly modified protocol was used. Briefly, frozen tissues were homogenized in cold buffer A (10 mM Tris- $\mathrm{HCl}$ at $\mathrm{pH} 8,1.5 \mathrm{mM} \mathrm{MgCl}_{2}, 10 \mathrm{mM} \mathrm{KCl}, 1 \mathrm{mM}$ DTT, $2 \times$ protease inhibitor cocktail) with a Potter homogenizer. After incubation on ice for $15 \mathrm{~min}$, samples were pelleted by centrifugation and resuspended in cold buffer A containing $0.1 \%$ Triton X-100. After incubation on ice, cells were pelleted, and nuclear pellets were resuspended in cold buffer C $(20 \mathrm{mM}$ Tris- $\mathrm{HCl}$ at $\mathrm{pH} 8,25 \%$ glycerol $[\mathrm{v} / \mathrm{v}], 0.4 \mathrm{M} \mathrm{NaCl}, 1.5 \mathrm{mM}$ $\mathrm{MgCl}_{2}, 0.2 \mathrm{mM}$ EDTA, $0.5 \mathrm{mM}$ DTT, $2 \times$ protease inhibitor cocktail). Samples were vigorously rocked for $15 \mathrm{~min}$ at $4^{\circ} \mathrm{C}$ on a shaking platform. The nuclear extracts were finally centrifuged for $5 \mathrm{~min}$ in a microfuge at $4^{\circ} \mathrm{C}$, and the supernatants were frozen in aliquots at $-70^{\circ} \mathrm{C}$. NF- $\mathrm{\kappa B}$ and Oct- 1 consensus oligonucleotides (Promega) were radiolabeled by T4 polynucleotide kinase (New England Biolabs) in the presence of $\gamma_{-}{ }^{32} \mathrm{P}$ ATP. Labeled oligonucleotides were incubated with 15-20 $\mu \mathrm{g}$ of nuclear extracts in $1 \times$ binding buffer $(4 \times$ glycerol, $20 \mathrm{mM}$ Tris- $\mathrm{HCl}$ at $\mathrm{pH} 8,60 \mathrm{mM} \mathrm{NaCl}, 5 \mathrm{mM} \mathrm{MgCl}_{2}, 1 \mathrm{mM} \mathrm{DTT}, 1 \times$ protease inhibitor cocktail) in the presence of poly-dI-dC. Complexes were run in nondenaturing, 6\% acrylamide gels, and exposed to X-ray detector Fuji PhosphorImager (Fujifilm Global).

\section{Western blot analysis}

Cultured cells were washed twice with $1 \times$ PBS and resuspended in $100 \mathrm{mM}$ Tris-HCl (pH 7.4), 2\% SDS, and $50 \mathrm{mM}$ EDTA. Tissues were snap-frozen in liquid nitrogen. Frozen tissues ( $\sim 50 \mathrm{mg}$ in each sample) were homogenized in $300 \mu \mathrm{L}$ of $100 \mathrm{mM}$ Tris- $\mathrm{HCl}$ (pH 7.4), $2 \%$ SDS, and $50 \mathrm{mM}$ EDTA with a Polytron homogenizer. Protein concentration was evaluated with the bicinchoninic acid technique (Pierce BCA protein assay kit). Equal amounts of proteins were loaded onto SDSpolyacrylamide gels. After electrophoresis, gels were electrotransferred onto nitrocellulose membranes or Immobilon-FL polyvinylidene fluoride membranes (Millipore), blocked with $5 \%$ nonfat dry milk in TBS-T buffer $(20 \mathrm{mM}$ Tris at $\mathrm{pH} 7.4$, $150 \mathrm{mM} \mathrm{NaCl}, 0.05 \%$ Tween 20 ), and incubated overnight at $4{ }^{\circ} \mathrm{C}$ with the different primary antibodies. Finally, blots were incubated with 1:10,000 secondary antibody conjugated with horseradish peroxidase (HRP) (Jackson ImmunoResearch Laboratories) in $1.5 \%$ nonfat milk in TBS-T. Then, we washed and developed the immunoreactive bands with Immobilon Western chemiluminescent HRP substrate (Millipore). 
Immunohistochemistry and immunofluorescence analysis

Formalin-fixed paraffin-embedded tissue sections were cut at $5 \mu \mathrm{m}$ for immunohistochemical detection of Ki67 on a Discover automated immunostainer (Ventana Medical Systems). Deparaffinization and heat-induced antigen retrieval were performed directly on the stainer. Antigen retrieval procedures were as follows: Retrieval was performed with CC2 solution (Ventana Medical Systems) for $30 \mathrm{~min}$ at $95^{\circ} \mathrm{C}$. Primary antibody incubation was performed for $1 \mathrm{~h}$ at $37^{\circ} \mathrm{C}$. Finally, HRP-conjugated antibody (OmniMap anti-Rb HRP, Ventana Medical Systems) was applied for $16 \mathrm{~min}$ at $37^{\circ} \mathrm{C}$. Staining was visualized by using ChromoMap DAB kit (Ventana Medical Systems). Cells were counterstained with hematoxylin and visualized by light microscopy. Quantitative analyses were performed according to the percentage of immunopositive cells per $0.5 \mathrm{~mm}$. For the immunofluorescence analysis, cells were fixed in $4 \%$ paraformaldehyde solution, rinsed in PBS, and permeabilized with $0.5 \%$ Triton X-100. Cells were incubated with primary antibodies diluted in $15 \%$ goat serum in $1 \times$ PBS for $1-3 \mathrm{~h}$ at room temperature. After washes with PBS, slides were incubated with 1:500 Alexa 488-conjugated secondary antibody (Life Technologies) for $1 \mathrm{~h}$ at $25^{\circ} \mathrm{C}$. After the final washes, nuclei were counterstained with DAPI (Roche), and slides were mounted in VectaShield mounting medium (Vector Laboratories). Microphotographs were recorded with an Axioplan-2 Zeiss fluorescent microscope (Zeiss), and images were captured with a chargecoupled device camera (Photometrics SenSys).

\section{RNA preparation and quantitative RT-PCR ( $q R T-P C R)$}

Cells were resuspended in TRIzol reagent (Life Technologies) and processed through alcohol precipitation. RNA pellets were then washed in cold $75 \%$ ethanol and resuspended in nuclease-free water (Ambion). The samples were quantified and evaluated for purity (260/280 nm ratio) with a NanoDrop ND-1000 spectrophotometer. cDNA was synthesized with 1-4 $\mu$ g of total RNA with the ThermoScript RT-PCR system (Invitrogen). qRT-PCR was carried out in triplicate for each sample with $20 \mathrm{ng}$ of cDNA, Power SYBR Green PCR Master Mix, and $0.5 \mu \mathrm{L}$ of the specific oligonucleotides for the gene of interest (Applied Biosystems). As an internal control for the amount of template cDNA used, gene expression was normalized to amounts obtained for the mouse Gapdh endogenous control. The following oligonucleotides were used for mouse Atm and Ikbkg (Nemo) amplification: Atm_fwd (5'-GGAGACAGCTTGTGAAGGGCCG-3'), Atm_rev (5'-TG CACCACTCGAGAACACCGC-3'), Ikbkg_fwd (5'-TGCCAAC AGCAGATGGCTGAGG-3'), and Ikbkg_rev (5'-GCTGTAGCA CCTCCCGCTCAC-3').

\section{Blood and plasma parameters}

Blood was extracted directly from the mandibular sinus after anesthetizing mice with isoflurane. Serum IL- 6, CXCL1, and TNF- $\alpha$ concentrations were determined by ELISA (IL-6, reference 887064-22, eBioscience; CXCL1, reference MKC00B, R\&D Systems; and TNF- $\alpha$, reference 88-7324-22, eBioscience). All protocols were performed according to the manufacturer's instructions.

\section{Transcriptional profiling}

Zmpste24-deficient mouse liver transcriptional profiles as well as $L m n a^{G 609 G}$ profiles were previously reported (Varela et al. 2005; Osorio et al. 2011a). Array data were clustered using Cluster 3.0 software, and the heat maps were created using TreeView 1.1.5 software (http://rana.lbl.gov/EisenSoftware.htm).
GSEA

GSEA was performed as described in the original citation (Subramanian et al. 2005). For data analysis, we used GSEA release 2.06 and MSigDB release 2.5 (http://www.broadinstitute. org/gsea/index.jsp). Weighted enrichment scores were calculated with gene expression lists ranked by signal to noise ratio. The maximum gene set size was set to 500 genes, the minimum gene set size was set to 20 genes, and the number of permutations was set to 1000. Analyses were performed with a gene set composed of genes that contain, in the promoter regions $[-2 \mathrm{~kb}, 2 \mathrm{~kb}]$ around the transcription start site, the motif GGGRATTTCC, which matches the consensus binding site for the NF- $\mathrm{kB}$ transcription factor. Selected enriched pathways had a relaxed false discovery rate of $<0.25$ and $P<0.05$.

\section{Statistical analysis}

We performed statistical analysis of the differences between mouse cohorts or different conditions with a two-tailed Student's $t$-test. In experiments with more than two groups, differences were analyzed by multifactorial one-way analysis of variance (ANOVA), and for the comparison of different groups in KaplanMeier survival plots, we used a log-rank (Mantel-Cox) test. We used Microsoft Excel or GraphPad Prism software for calculations and expressed the results as the means \pm SEM.

\section{Acknowledgments}

We thank Drs. G. Velasco, X.S. Puente, N. Lévy, M.S. Fernández, L. Boscá, O. Fernández-Capetillo, and J. Rivera for their support and assistance. This work was supported by grants from Ministerio de Ciencia e Innovación-Spain and European Union (FP7 MicroEnviMet). The Instituto Universitario de Oncología is supported by Obra Social Cajastur and Acción Transversal del Cáncer-RTICC. C.L.-O. is an Investigator of the Botin Foundation.

\section{References}

Adler AS, Sinha S, Kawahara TL, Zhang JY, Segal E, Chang HY. 2007. Motif module map reveals enforcement of aging by continual NF-кB activity. Genes Dev 21: 3244-3257.

Aw D, Palmer DB. 2011. The origin and implication of thymic involution. Aging Dis 2: 437-443.

Baker DJ, Wijshake T, Tchkonia T, LeBrasseur NK, Childs BG, van de Sluis B, Kirkland JL, van Deursen JM. 2011. Clearance of p16Ink4a-positive senescent cells delays ageing-associated disorders. Nature 479: 232-236.

Beg AA, Sha WC, Bronson RT, Ghosh S, Baltimore D. 1995. Embryonic lethality and liver degeneration in mice lacking the RelA component of NF-кB. Nature 376: 167-170.

Bensimon A, Aebersold R, Shiloh Y. 2011. Beyond ATM: The protein kinase landscape of the DNA damage response. FEBS Lett 585: 1625-1639.

Bergo MO, Gavino B, Ross J, Schmidt WK, Hong C, Kendall LV, Mohr A, Meta M, Genant H, Jiang Y, et al. 2002. Zmpste24 deficiency in mice causes spontaneous bone fractures, muscle weakness, and a prelamin A processing defect. Proc Natl Acad Sci 99: 13049-13054.

Biton S, Ashkenazi A. 2011. NEMO and RIP1 control cell fate in response to extensive DNA damage via TNF- $\alpha$ feedforward signaling. Cell 145: 92-103.

Burtner CR, Kennedy BK. 2010. Progeria syndromes and ageing: What is the connection? Nat Rev Mol Cell Biol 11: 567-578.

Cai D, Frantz JD, Tawa NE Jr, Melendez PA, Oh BC, Lidov HG, Hasselgren PO, Frontera WR, Lee J, Glass DJ, et al. 2004. 
IKK $\beta /$ NF-кB activation causes severe muscle wasting in mice. Cell 119: 285-298.

Coppe JP, Desprez PY, Krtolica A, Campisi J. 2010. The senescence-associated secretory phenotype: The dark side of tumor suppression. Annu Rev Pathol 5: 99-118.

de Carlos F, Varela I, Germana A, Montalbano G, Freije JM, Vega JA, Lopez-Otin C, Cobo JM. 2008. Microcephalia with mandibular and dental dysplasia in adult Zmpste24-deficient mice. I Anat 213: 509-519.

Dechat T, Pfleghaar K, Sengupta K, Shimi T, Shumaker DK, Solimando L, Goldman RD. 2008. Nuclear lamins: Major factors in the structural organization and function of the nucleus and chromatin. Genes Dev 22: 832-853.

De Sandre-Giovannoli A, Bernard R, Cau P, Navarro C, Amiel J, Boccaccio I, Lyonnet S, Stewart CL, Munnich A, Le Merrer M, et al. 2003. Lamin a truncation in Hutchinson-Gilford progeria. Science 300: 2055. doi: 10.1126/science.1084125.

Eriksson M, Brown WT, Gordon LB, Glynn MW, Singer J, Scott L, Erdos MR, Robbins CM, Moses TY, Berglund P, et al. 2003. Recurrent de novo point mutations in lamin A cause Hutchinson-Gilford progeria syndrome. Nature 423: 293-298.

Espada J, Varela I, Flores I, Ugalde AP, Cadinanos J, Pendas AM, Stewart CL, Tryggvason K, Blasco MA, Freije JM, et al. 2008. Nuclear envelope defects cause stem cell dysfunction in premature-aging mice. J Cell Biol 181: 27-35.

Freije JM, Lopez-Otin C. 2012. Reprogramming aging and progeria. Curr Opin Cell Biol doi: 10.1016/j.ceb.2012.08.009.

Freund A, Orjalo AV, Desprez PY, Campisi J. 2010. Inflammatory networks during cellular senescence: Causes and consequences. Trends Mol Med 16: 238-246.

Gruenbaum Y, Margalit A, Goldman RD, Shumaker DK, Wilson KL. 2005. The nuclear lamina comes of age. Nat Rev Mol Cell Biol 6: 21-31.

Hale JS, Frock RL, Mamman SA, Fink PJ, Kennedy BK. 2010. Cell-extrinsic defective lymphocyte development in $\mathrm{Lmna}^{-1-}$ mice. PLOS ONE 5: e10127. doi: 10.1371/journal.pone. 0010127.

Hayden MS, Ghosh S. 2004. Signaling to NF-кB. Genes Dev 18: 2195-2224.

Hayden MS, Ghosh S. 2008. Shared principles in NF-кB signaling. Cell 132: 344-362.

Hayden MS, Ghosh S. 2012. NF-кB, the first quarter-century: Remarkable progress and outstanding questions. Genes Dev 26: $203-234$.

Hennekam RC. 2006. Hutchinson-Gilford progeria syndrome: Review of the phenotype. Am I Med Genet A 140: 26032624.

Herweijer H, Wolff JA. 2007. Gene therapy progress and prospects: Hydrodynamic gene delivery. Gene Ther 14: 99-107.

Hoeijmakers JH. 2009. DNA damage, aging, and cancer. N Engl J Med 361: 1475-1485.

Huang TT, Wuerzberger-Davis SM, Wu ZH, Miyamoto S. 2003. Sequential modification of NEMO/IKK $\gamma$ by SUMO-1 and ubiquitin mediates NF- $\mathrm{KB}$ activation by genotoxic stress. Cell 115: 565-576.

Janssens S, Tschopp J. 2006. Signals from within: The DNAdamage-induced NF-кB response. Cell Death Differ 13: 773784.

Kang TW, Yevsa T, Woller N, Hoenicke L, Wuestefeld T, Dauch D, Hohmeyer A, Gereke M, Rudalska R, Potapova A, et al. 2011. Senescence surveillance of pre-malignant hepatocytes limits liver cancer development. Nature 479: 547-551.

Kawahara TL, Michishita E, Adler AS, Damian M, Berber E, Lin M, McCord RA, Ongaigui KC, Boxer LD, Chang HY, et al. 2009. SIRT6 links histone H3 lysine 9 deacetylation to NF- $\kappa \mathrm{B}-$ dependent gene expression and organismal life span. Cell 136: $62-74$.

Kirkwood TB. 2005. Understanding the odd science of aging. Cell 120: 437-447.

Kuilman T, Peeper DS. 2009. Senescence-messaging secretome: SMS-ing cellular stress. Nat Rev Cancer 9: 81-94.

Lammerding J, Schulze PC, Takahashi T, Kozlov S, Sullivan T, Kamm RD, Stewart CL, Lee RT. 2004. Lamin A/C deficiency causes defective nuclear mechanics and mechanotransduction. J Clin Invest 113: 370-378.

Lavin MF. 2008. Ataxia-telangiectasia: From a rare disorder to a paradigm for cell signalling and cancer. Nat Rev Mol Cell Biol 9: 759-769.

Le Saux S, Weyand CM, Goronzy IJ. 2012. Mechanisms of immunosenescence: Lessons from models of accelerated immune aging. Ann N Y Acad Sci 1247: 69-82.

Li Q, Verma IM. 2002. NF-кB regulation in the immune system. Nat Rev Immunol 2: 725-734.

Liu B, Wang J, Chan KM, Tjia WM, Deng W, Guan X, Huang JD, Li KM, Chau PY, Chen DJ, et al. 2005. Genomic instability in laminopathy-based premature aging. Nat Med 11: 780-785.

Marino G, Ugalde AP, Salvador-Montoliu N, Varela I, Quiros PM, Cadinanos J, van der Pluijm I, Freije JM, Lopez-Otin C. 2008. Premature aging in mice activates a systemic metabolic response involving autophagy induction. Hum Mol Genet 17: 2196-2211.

Marino G, Ugalde AP, Fernandez AF, Osorio FG, Fueyo A, Freije JM, Lopez-Otin C. 2010. Insulin-like growth factor 1 treatment extends longevity in a mouse model of human premature aging by restoring somatotroph axis function. Proc Natl Acad Sci 107: 16268-16273.

McCool KW, Miyamoto S. 2012. DNA damage-dependent NF$\kappa \mathrm{B}$ activation: NEMO turns nuclear signaling inside out. Immunol Rev 246: 311-326.

Mekhail K, Moazed D. 2010. The nuclear envelope in genome organization, expression and stability. Nat Rev Mol Cell Biol 11: 317-328.

Merideth MA, Gordon LB, Clauss S, Sachdev V, Smith AC, Perry MB, Brewer CC, Zalewski C, Kim HJ, Solomon B, et al. 2008. Phenotype and course of Hutchinson-Gilford progeria syndrome. N Engl J Med 358: 592-604.

Miyamoto S. 2011. Nuclear initiated NF-кB signaling: NEMO and ATM take center stage. Cell Res 21: 116-130.

Osorio FG, Varela I, Lara E, Puente XS, Espada J, Santoro R, Freije JM, Fraga MF, Lopez-Otin C. 2010. Nuclear envelope alterations generate an aging-like epigenetic pattern in mice deficient in Zmpste24 metalloprotease. Aging Cell 9: 947957.

Osorio FG, Navarro CL, Cadinanos J, Lopez-Mejia IC, Quiros PM, Bartoli C, Rivera J, Tazi J, Guzman G, Varela I, et al. 2011a. Splicing-directed therapy in a new mouse model of human accelerated aging. Sci Transl Med 3: 106ra107. doi: 10.1126/scitranslmed.3002847.

Osorio FG, Ugalde AP, Marino G, Puente XS, Freije JM, LopezOtin C. 2011b. Cell autonomous and systemic factors in progeria development. Biochem Soc Trans 39: 1710-1714.

Pendas AM, Zhou Z, Cadinanos J, Freije JM, Wang J, Hultenby K, Astudillo A, Wernerson A, Rodriguez F, Tryggvason K, et al. 2002. Defective prelamin A processing and muscular and adipocyte alterations in Zmpste24 metalloproteinasedeficient mice. Nat Genet 31: 94-99.

Perkins ND. 2007. Integrating cell-signalling pathways with NFкB and IKK function. Nat Rev Mol Cell Biol 8: 49-62.

Puente XS, Quesada V, Osorio FG, Cabanillas R, Cadinanos J, Fraile JM, Ordonez GR, Puente DA, Gutierrez-Fernandez A, Fanjul-Fernandez M, et al. 2011. Exome sequencing and 
functional analysis identifies BANF1 mutation as the cause of a hereditary progeroid syndrome. Am J Hum Genet 88: 650-656.

Ramirez CL, Cadinanos J, Varela I, Freije JM, Lopez-Otin C. 2007. Human progeroid syndromes, aging and cancer: New genetic and epigenetic insights into old questions. Cell Mol Life Sci 64: 155-170.

Rando TA, Chang HY. 2012. Aging, rejuvenation, and epigenetic reprogramming: Resetting the aging clock. Cell 148: 46-57.

Ricciotti E, FitzGerald GA. 2011. Prostaglandins and inflammation. Arterioscler Thromb Vasc Biol 31: 986-1000.

Rodier F, Coppe JP, Patil CK, Hoeijmakers WA, Munoz DP, Raza SR, Freund A, Campeau E, Davalos AR, Campisi J. 2009. Persistent DNA damage signalling triggers senescenceassociated inflammatory cytokine secretion. Nat Cell Biol 11: 973-979.

Sagelius H, Rosengardten Y, Hanif M, Erdos MR, Rozell B, Collins FS, Eriksson M. 2008. Targeted transgenic expression of the mutation causing Hutchinson-Gilford progeria syndrome leads to proliferative and degenerative epidermal disease. J Cell Sci 121: 969-978.

Salminen A, Suuronen T, Huuskonen J, Kaarniranta K. 2008. NEMO shuttle: A link between DNA damage and NF-кB activation in progeroid syndromes? Biochem Biophys Res Commun 367: 715-718.

Salminen A, Ojala J, Kaarniranta K. 2011. Apoptosis and aging: Increased resistance to apoptosis enhances the aging process. Cell Mol Life Sci 68: 1021-1031.

Scaffidi P, Misteli T. 2006. Lamin A-dependent nuclear defects in human aging. Science 312: 1059-1063.

Scaffidi P, Misteli T. 2008. Lamin A-dependent misregulation of adult stem cells associated with accelerated ageing. Nat Cell Biol 10: 452-459.

Schreiber E, Matthias P, Muller MM, Schaffner W. 1989. Rapid detection of octamer binding proteins with 'mini-extracts', prepared from a small number of cells. Nucleic Acids Res 17: 6419. doi: 10.1093/nar/17.15.6419.

Subramanian A, Tamayo P, Mootha VK, Mukherjee S, Ebert BL, Gillette MA, Paulovich A, Pomeroy SL, Golub TR, Lander ES, et al. 2005. Gene set enrichment analysis: A knowledgebased approach for interpreting genome-wide expression profiles. Proc Natl Acad Sci 102: 15545-15550.

Sur I, Ulvmar M, Toftgard R. 2008. The two-faced NF-кB in the skin. Int Rev Immunol 27: 205-223.

Tak PP, Firestein GS. 2001. NF-кB: A key role in inflammatory diseases. J Clin Invest 107: 7-11.

Tilstra JS, Clauson CL, Niedernhofer LJ, Robbins PD. 2011. NF$\kappa \mathrm{B}$ in aging and disease. Aging Dis 2: 449-465.

Tilstra JS, Robinson AR, Wang J, Gregg SQ, Clauson CL, Reay DP, Nasto LA, St Croix CM, Usas A, Vo N, et al. 2012. NF-кB inhibition delays DNA damage-induced senescence and aging in mice. J Clin Invest 122: 2601-2612.

Ugalde AP, Espanol Y, Lopez-Otin C. 2011a. Micromanaging aging with miRNAs: New messages from the nuclear envelope. Nucleus 2: 549-555.

Ugalde AP, Ramsay AJ, de la Rosa J, Varela I, Marino G, Cadinanos J, Lu J, Freije JM, Lopez-Otin C. 2011b. Aging and chronic DNA damage response activate a regulatory pathway involving miR-29 and p53. EMBO J 30: 2219-2232.

Varela I, Cadinanos J, Pendas AM, Gutierrez-Fernandez A, Folgueras AR, Sanchez LM, Zhou Z, Rodriguez FJ, Stewart CL, Vega JA, et al. 2005. Accelerated ageing in mice deficient in Zmpste24 protease is linked to p53 signalling activation. Nature 437: 564-568.

Varela I, Pereira S, Ugalde AP, Navarro CL, Suarez MF, Cau P, Cadinanos J, Osorio FG, Foray N, Cobo J, et al. 2008.
Combined treatment with statins and aminobisphosphonates extends longevity in a mouse model of human premature aging. Nat Med 14: 767-772.

Vijg J, Campisi J. 2008. Puzzles, promises and a cure for ageing. Nature 454: 1065-1071.

Wang CY, Cusack JC Jr, Liu R, Baldwin AS Jr. 1999. Control of inducible chemoresistance: Enhanced anti-tumor therapy through increased apoptosis by inhibition of NF-кB. Nat Med 5: 412-417.

Wang Y, Panteleyev AA, Owens DM, Djabali K, Stewart CL, Worman HJ. 2008. Epidermal expression of the truncated prelamin A causing Hutchinson-Gilford progeria syndrome: Effects on keratinocytes, hair and skin. Hum Mol Genet 17: 2357-2369.

Worman HJ, Foisner R. 2010. The nuclear envelope from basic biology to therapy. Biochem Soc Trans 38: 253-256.

Worman HJ, Ostlund C, Wang Y. 2010. Diseases of the nuclear envelope. Cold Spring Harb Perspect Biol 2: a000760. doi: 10.1101/cshperspect.a000760.

Wu ZH, Shi Y, Tibbetts RS, Miyamoto S. 2006. Molecular linkage between the kinase ATM and NF- $\mathrm{B}$ signaling in response to genotoxic stimuli. Science 311: 1141-1146. 


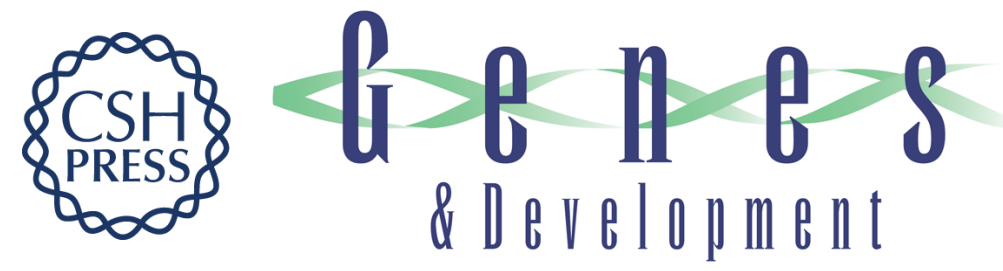

\section{Nuclear lamina defects cause ATM-dependent NF- $\kappa$ B activation and link accelerated aging to a systemic inflammatory response}

Fernando G. Osorio, Clea Bárcena, Clara Soria-Valles, et al.

Genes Dev. 2012, 26: originally published online September 26, 2012

Access the most recent version at doi:10.1101/gad.197954.112

\section{Supplemental http://genesdev.cshlp.org/content/suppl/2012/09/25/gad.197954.112.DC1 Material}

References This article cites 72 articles, 16 of which can be accessed free at: http://genesdev.cshlp.org/content/26/20/2311.full.html\#ref-list-1

\section{License}

Email Alerting

Service

Receive free email alerts when new articles cite this article - sign up in the box at the top right corner of the article or click here.

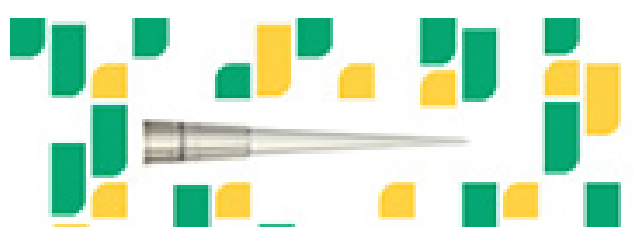

Focused on your science. 